Universidade de São Paulo

Instituto de Física

\title{
Estudo teórico de propriedades eletrônicas e da solvatação de carbonatos orgânicos em meio aquoso
}

\author{
FERNANDO DA SILVA
}

Dissertação apresentada ao Instituto de Física para a obtenção do título de Mestre em Ciências.

Orientador: Prof. Dr. Sylvio Roberto Accioly Canuto

Banca Examinadora:

Prof. Dr. Sylvio Roberto Accioly Canuto (IFUSP)

Prof. Dr. Marcio Teixeira do Nascimento Varella (IFUSP)

Prof. Dr. Luiz Carlos Gomide Freitas (IQ/UFSCar) 
FICHA CATALOGRÁFICA

Preparada pelo Serviço de Biblioteca e Informação do Instituto de Física da Universidade de São Paulo

Silva, Fernando da

Estudo teórico de propriedades eletrônicas e da solvatação de carbonatos orgânicos em meio aquoso São Paulo, 2011.

Dissertação (Mestrado) - Universidade de São Paulo. Instituto de Física - Depto. de Física Geral

Orientador: Prof. Dr. Sylvio Roberto Accioly Canuto

Área de Concentração: Física Atômica e Molecular

Unitermos: 1.Física Computacional; 2. Química

Quântica; 3.Solvatação; 4. Soluções Aquosas 
"É preciso que não tenham medo de dizer alguma coisa que possa ser considerada como erro.

Porque tudo que é novo, aparece aos olhos antigos como coisa errada. É sempre nesta violação do que é considerado certo, que nasce o novo e há a criação. E este espírito deve ser redescoberto pela juventude brasileira"

Mário Schenberg. 



\section{Agradecimentos}

Agradeço ao CNPq e à FAPESP (processo no: 2009/03635-1) pelo apoio financeiro.

Agradeço aos meus pais que, desde o início, foram os meus grandes incentivadores.

No decorrer deste anos de estudos, também foram muitos os amigos com quem pude conviver. Muitos já se perderam pela vida, mas ainda assim agradeço a cada um pelo incentivo, pela força nos momentos difíceis e por tantas alegrias.

Agradeço aos integrantes do Grupo de Física Molecular e Modelagem, companheiros de batalha no "exército da solvatação". Agradeço especialmente à Prof. ${ }^{a}$ Kaline Coutinho, que foi quem guiou na arte da simulação computacional.

E, por último, não poderia deixar de agradecer ao prof. Sylvio Canuto, pelos anos de orientação, respeito, amizade e de ensinamentos, não só sobre Ciência, mas também sobre a vida. O professor é um exemplo de caráter, de ética profissional e de mestre. Para nós, fazer parte de seu grupo, é uma grande honra e ao mesmo tempo um grande desafio. Sou imensamente grato pelo convite de fazer parte de seu "exército", pela confiança em mim depositada, sem a qual talvez não estivesse chegado até aqui.

Enfim, foram muitos os que torceram, rezaram, apoiaram e foram fundamentais para que este trabalho fosse concluído.

À todos o meu muito Obrigado, Fernando da Silva. 



\section{Resumo}

Neste trabalho, uma combinação de cálculos de mecânica quântica, simulações computacionais e teoria de perturbação termodinâmica foi usada para estudar a solvatação do carbonato de etileno (EC) e do carbonato de propileno (PC) em água. As estruturas do líquido foram geradas usando simulações com o método Monte Carlo e amostragem de Metropolis. A função de autocorrelação em energia foi usada para analisar a correlação estatística entre estas configurações. Após uma análise detalhada das ligações de hidrogênio, configurações supermoleculares descorrelacionadas (carbonatos + ligações de hidrogênio cercadas por 350 moléculas de água tratadas como cargas pontuais) foram amostradas das simulações e cálculos do momento de dipolo, no nível de cálculo MP2/aug-cc-pvDZ, foram realizados. Em média, foram formadas 1,4 ligações de hidrogênio entre a água e os solutos (EC ou PC). Foi obtido um momento de dipolo médio de 9,9 \pm 0,2 D para o EC-água e de $10,6 \pm 0,2 \mathrm{D}$ para o PC-água. Finalmente, simulações com o método de Monte Carlo no ensemble NPT e a técnica de perturbação de energia livre foram usados para determinar as energias livres de solvatação, e os resultados foram $\Delta G_{\text {solv }}=-15,1 \pm 0,8 \mathrm{kcal} / \mathrm{mol}$ para 0 EC em água e $\Delta G_{\text {solv }}=-15,3 \pm 1,2 \mathrm{kcal} / \mathrm{mol}$ para o $\mathrm{PC}$ em água. A análise destes resultados leva a conclusão de que o EC e o PC são igualmente estáveis em solução aquosa, ou seja, a metilação não tem efeito significativo na solvatação do PC e nem influencia a formação das ligações de hidrogênio. 



\section{Abstract}

In this work, a combination of quantum mechanics, Monte Carlo simulations and thermodynamic perturbation theory was used to study the solvation of ethylene carbonate (EC) and propylene carbonate (PC) in water. The liquid structures was generated by NVT Monte Carlo simulation using standard procedures for the Metropolis sampling technique. The auto-correlation function of the energy was used to analyze the statistical correlation between the configurations. After a detailed analysis of the hydrogen bonds, super-molecular uncorrelated configurations (carbonates + hydrogen bonds sorrounded by 350 water molecules treated as point charges) were sampled from the simulations and dipole moment calculations, at the MP2/aug-cc-pvDZ, were performed. On average, 1.4 hydrogen bonds were formed between water and the solutes (EC or PC). An average dipole moment of $9.9 \pm 0.2 \mathrm{D}$ was obtained for EC-water and $10.6 \pm 0.2 \mathrm{D}$ for PC-water. Finally, Monte Carlo simulations in the NPT ensemble combined with free energy perturbation technique were used to determine solvation free energies, and the results were $\Delta G_{\text {solv }}=-15.1 \pm 0.8 \mathrm{kcal} / \mathrm{mol}$ for EC in water and $\Delta G_{\text {solv }}=-15.3 \pm 1.2 \mathrm{kcal} / \mathrm{mol}$ for $\mathrm{PC}$ in water. The analysis of these results leads to the conclusion that $\mathrm{EC}$ and $\mathrm{PC}$ are equally stable in aqueous solution, i.e., the methylation has no effect on the solvation of $\mathrm{PC}$ and no influence on the hydrogen bond formation. 



\section{Sumário}

Lista de Figuras $\quad$ xiii

Lista de Tabelas $\quad$ xv

1 Introdução 1

2 Metodologia teórica: sistemas isolados 5

2.1 A aproximação de Born-Oppenheimer . . . . . . . . . . . . . . . 5

2.2 O Método de Hartree-Fock . . . . . . . . . . . . . . . . . . . . . . 7

2.2 .1 O método de Hartree-Fock-Roothaan . . . . . . . . . . . . 11

2.3 Funções Base . . . . . . . . . . . . . . . . . . . . . . . . . . . . . . . 13

2.4 Correlação eletrônica . . . . . . . . . . . . . . . . . . . . . . . . . . . 16

2.5 Aproximações perturbativas . . . . . . . . . . . . . . . . . . . . . . 19

2.6 Aplicacones . . . . . . . . . . . . . . . . . . . . . . . . . . . . 22

2.6.1 Análise de população e a metodologia CHELPG . . . . . . . . . 23

3 Metodologia teórica: moléculas em solução 25

3.1 Energia livre de solvatação . . . . . . . . . . . . . . . . . . 25

3.1 .1 Os modelos contínuos . . . . . . . . . . . . . . . . 27

3.1 .2 O modelo contínuo polarizável . . . . . . . . . . . . . . . . . 29

3.1 .3 Limitações dos modelos de solvatação implícita . . . . . . . . . 30

3.2 Simulação Computacional . . . . . . . . . . . . . . . . . . . . . . . 31

3.2 .1 O potencial de interação . . . . . . . . . . . . . . . . 32

3.2 .2 O método Monte Carlo . . . . . . . . . . . . . . . . . . 33

3.2 .3 Análise da simulação . . . . . . . . . . . . . . . . . 37 
3.3 Teoria de perturbação termodinâmica e energia livre de solvatação . . . 38

3.4 A metodologia $\mathrm{S}-\mathrm{QM} / \mathrm{MM} \ldots \ldots \ldots \ldots$. . . . . . . . . . . . . 40

3.4 .1 Médias, erros e ineficiência estatística . . . . . . . . . . . . 42

\begin{tabular}{|ll|}
\hline 4 & Resultados
\end{tabular}

4.1 Moléculas isoladas . . . . . . . . . . . . . . . . . . . 45

4.2 Solvatação implícital . . . . . . . . . . . . . . . . . . . 50

4.3 Simulação computacional . . . . . . . . . . . . . . . . . . . . 52

4.3 .1 Ligações de hidrogênio . . . . . . . . . . . . . . . . 54

4.4 Energia livre de solvatação . . . . . . . . . . . . . . . . 60

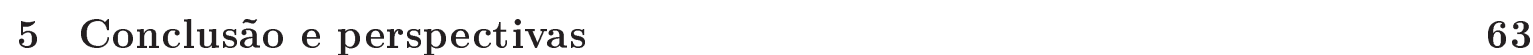

$\begin{array}{ll}\text { Referências Bibliográficas } & 65\end{array}$ 


\section{Lista de Abreviaturas}

\begin{tabular}{ll} 
AMBER & Assisted Model Building with Energy Refinement \\
BC & Butylene Carbonate \\
CC & Born-Oppenheimer \\
CHELPG & Coupled-Cluster \\
CI & Configuration Interaction \\
DZ & Double Zeta \\
DZ & Triple Zeta \\
EC & Ethylene Carbonate \\
GC & Glycerine Carbonate \\
GTO & Gaussian-type Orbital \\
HF & Hartree-Fock \\
LH & Ligação de hidrogênio \\
& Lennard Jones + Coulomb \\
MC & Carlo \\
\hline &
\end{tabular}


MD Molecular Dynamics

MDDF Minimum Distance Distribution Function

MPPT Møller Plesset Perturbation Theory

OPLS Optimized Parameter for Liquid Simulation

PC Propylene Carbonate

PCM Polarizable Continuum Model

QM/MM Quantum Mechanics/ Molecular Mechanics

RDF Radial Distribution Function

RHF Restricted Hartree-Fock

RSPT Rayleigh-Schrödinger Perturbation Theory

S-QM/MM Sequential Quantum Mechanics/ Molecular Mechanics

SCF Self Consistent Field

SCRF Self Consistent Reaction Field

SPC Single Point Charge

STO Slater-type Orbital

UAHF United Atom Topological Model 


\section{Lista de Figuras}

1.1 Estrutura de alguns dos carbonatos orgânicos cíclicos mais comuns . . . 1

4.1 Geometrias do EC e do $\mathrm{PC} \ldots \ldots \ldots \ldots . \ldots . \ldots 46$

4.2 Ajuste da função de autocorrelação em energia . . . . . . . . . . . . . . 53

4.3 Critérios de distância e ângulo . . . . . . . . . . . . . . . . . 54

4.4 Funcõos de distribuicãão radial de pares $\ldots \ldots \ldots$. . . . . . . . . . 55

4.5 Energia de ligação entre os pares soluto-solvente . . . . . . . . . . . 56

4.6 Superposição de 100 configurações do soluto + LH . . . . . . . . . . . 57

4.7 Representação de uma das configurações usadas no cálculo do dipolo . 58

4.8 Ciclo termodinâmico . . . . . . . . . . . . . . . . . . . . . 60 


\section{Lista de Tabelas}

4.1 Parâmetros estruturais para o EC e Pd . . . . . . . . . . . . 48

4.2 Ajuste de cargas usando CHELPG . . . . . . . . . . . . . 50

4.3 Energia livre de solvatação calculada usando o PCM . . . . . . . . . 51

4.4 Parâmetros do potencial de Lennard-Jones e Coulomb . . . . . . . . . . 53

4.5 Distribuição das LH . . . . . . . . . . . . . . . . . . . . 57

4.6 Momento de dipolo de complexos carbonato-LH . . . . . . . . . . . 59

4.7 Energia livre de solvatação calculada com FEP . . . . . . . . . . . 62 


\section{Capítulo 1}

\section{Introdução}

Carbonatos orgânicos (figura 1.1) pertencem à classe dos solventes apróticos altamente dipolares. São notáveis por suas propriedades físicas, tais como alto ponto de ebulição, alto ponto de fusão, alta constante dielétrica e alto momento de dipolo. Estas propriedades, associadas a sua biodegradabilidade e baixa toxicidade tem favorecido suas aplicações industriais. Eles já têm sido amplamente usados como solventes em baterias de lítio, desde a década de 60, e o número de aplicações vem crescendo nos últimos anos, em áreas como a agricultura e indústria de cosméticos, por exemplo [1].

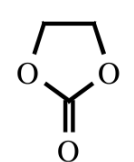

(a) EC

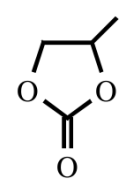

(b) $\mathrm{PC}$

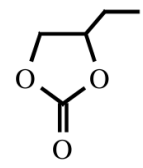

(c) $\mathrm{BC}$

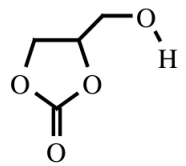

(d) GC

Figura 1.1: Estrutura de alguns dos carbonatos orgânicos cíclicos mais comuns: EC (ethylene carbonate), PC (propylene carbonate), BC (butylene carbonate) e GC (glycerine carbonate).

Com o aumento do número de aplicações, o interesse nestes carbonatos também cresceu e numerosos trabalhos relacionados com suas propriedades, tanto teóricos quanto experimentais, foram publicados recentemente. Dois artigos de revisão, o primeiro publicado em 1996 [2] e o segundo em 2010 [3], reúnem bastante informação sobre os carbonato orgânicos, desde suas propriedades físico-químicas até informações 
sobre a síntese, catálise e aplicações industriais. Também existem na literatura diversos artigos recentes experimentais, que tratam das propriedades termodinâmicas, como pressão de vapor e entalpia de vaporização [4], da constante dielétrica e do momento de dipolo [5] destas moléculas.

Dos trabalhos teóricos, destacam-se estudos das propriedades termoquímicas [6] e da associação entre estes carbonatos [7]. Também existem na literatura simulações computacionais de EC e PC como líquidos puros, usando tanto Dinâmica Molecular [8] quanto o método Monte Carlo [9]. Devido à ampla aplicação destes carbonatos como eletrólitos em baterias, diversos estudos sobre a dinâmica molecular de íons nestes carbonatos [10-15] também já foram realizadas.

Neste trabalho estudamos a solvatação de dois destes carbonatos orgânicos em solução aquosa: o carbonato de etileno (EC) e o carbonato de propileno (PC). É interessante notar que, embora haja um amplo estudo dos carbonatos orgânicos como solventes, não existem na literatura estudos teóricos sobre o comportamento destes carbonatos em solução aquosa. Estes carbonatos, no entanto, exibem um comportamento bastante distinto no que se refere a solubilidade: enquanto o EC é infinitamente solúvel em água o PC e o BC apresentam uma solubilidade extremamente baixa $(0,044$ mol de PC por mol de água e 0,011 mol de BC por mol de água, para uma temperatura de $\left.25^{\circ} \mathrm{C}\right)$.

Do ponto de vista teórico, EC e o PC solvatados em água são um sistema de interesse per se. Devido ao seu alto momento de dipolo, existe uma forte interação entre as moléculas de água do solvente e o soluto, sobretudo por meio de ligações de hidrogênio no grupo carbonato. Em um estudo sobre a solvatação diferencial do fenol e de seu radial fenóxido, Canuto et al [16] mostraram que o estudo das ligações de hidrogênio pode ser essencial para a correta descrição do processo de solvatação. Por esta razão, realizamos um detalhado estudo da distribuição destas ligações em configurações tiradas de simulações computacionais. 
Além do grupo carbonato, que é hidrofílico, os carbonatos orgânicos são caracterizados pelo seu grupo hidrofóbico e, como podemos observar na figura 1.1, a única diferença entre eles está no tamanho da cadeia carbônica agregada ao grupo carbonato. Ao estudarmos a solvatação destes carbonatos podemos, portanto, estudar como a cadeia carbônica influencia as propriedades destas moléculas em solução. Estudar sistemas com longas cadeias carbônicas, entretanto, demandam maior esforço computacional e esta é uma das razões para limitarmos o estudo as moléculas de EC e PC.

No primeiro capítulo deste trabalho são apresentados os métodos de mecânica quântica usados para a obtenção das geometrias de equilíbrio e no estudo de propriedades eletrônicas, em geral de sistemas isoladas, como o método de Hartree-Fock e aproximações perturbativas.

No capítulo 2 são apresentados os principais métodos usados atualmente no estudo de moléculas em solução: modelos contínuos e modelos baseados em simulação computacional (com o método Monte Carlo). O método QM/MM sequencial é discutido no tratamento de efeitos de solvente, bem como métodos para o cálculo da energia livre de solvatação das moléculas em água.

No capítulo seguinte, apresentamos e discutimos os resultados obtidos. Apresentamos neste capítulo os resultados para as geometrias de equilíbrio, momentos de dipolo das moléculas isoladas e em solução. Também são apresentadas os resultados da simulação computacional, o estudo das ligações de hidrogênio e os resultados para a energia livre de solvatação.

Finalmente, as conclusões e perspectivas do nosso trabalho são apresentadas no capítulo 4 . 


\section{Capítulo 2}

\section{Metodologia teórica: sistemas isolados}

A estrutura eletrônica e propriedades de qualquer molécula, em qualquer um de seus estados estacionários podem, em princípio, serem determinadas a partir da solução da equação de Schrödinger independente do tempo. A possibilidade de obter uma solução exata para um problema real de mecânica quântica é, na prática, uma situação bastante rara, sobretudo em um sistema de muitas partículas. Mesmo para a molécula mais simples, $H_{2}^{+}$, esta equação não pode ser resolvida exatamente. Desde os primórdios da teoria quântica uma importância considerável é conferida ao desenvolvimento, sistematização e uso de métodos de aproximação adaptados aos mais diversos problemas. Este capítulo trata das técnicas de aproximação de uso frequente no estudo de moléculas isoladas, enfatizando aqueles que são usados neste trabalho.

\subsection{A aproximação de Born-Oppenheimer}

A separação entre o movimento eletrônico e o movimento nuclear é, em geral, a primeira aproximação para a aplicação da mecânica quântica a sistemas moleculares. O fato intuitivo por detrás desta aproximação é que a razão entre as massas do elétron e do núcleo é pequena, o suficiente para que os núcleos não consigam acompanhar o rápido movimento eletrônico e possam ser considerados fixos. O desenvolvimento for- 
mal e sistemático desta ideia é conhecida como a aproximação de Born-Oppenheimer (BO). Em geral esta é uma excelente aproximação, sobretudo para o estado fundamental. Sua validade, no entanto, contém questões bem mais delicadas que simplesmente a razão entre as massas [17].

A equação de Schrödinger não relativística independente do tempo tem a forma

$$
\mathcal{H}|\Psi\rangle=\mathcal{E}|\Psi\rangle
$$

onde $\mathcal{H}$ é o operador hamiltoniano. Para um sistema molecular de $\mathrm{M}$ núcleos e $\mathrm{N}$ elétrons descritos, respectivamente, pelos vetores de posição $\mathbf{R}_{\mathbf{A}}$ e $\mathbf{r}_{\mathbf{i}}$, este operador tem a seguinte forma, em unidades atômicas (massa do elétron $m=1$, carga do elétron $e=1$, raio de Bohr $a_{0}=1$ e constante de Planck $\hbar=1$ ),

$$
\mathcal{H}=\underbrace{-\sum_{i=1}^{N} \frac{1}{2} \nabla_{i}^{2}}_{T_{e}}-\underbrace{-\sum_{A=1}^{N} \frac{1}{2} \nabla_{A}^{2}}_{T_{N}} \underbrace{-\sum_{i=1}^{N} \sum_{A=1}^{M} \frac{Z_{A}}{r_{i A}}}_{V_{e N}} \underbrace{+\sum_{i=1}^{N} \sum_{j>i}^{N} \frac{1}{r_{i j}}}_{V_{e e}} \underbrace{+\sum_{A=1}^{M} \sum_{B>A}^{M} \frac{Z_{A} Z_{B}}{R_{A B}}}_{V_{N N}} .
$$

Na equação acima $M_{A}$ é a massa nuclear, $r_{i j}=\left|\mathbf{r}_{\mathbf{i}}-\mathbf{r}_{\mathbf{j}}\right|, R_{i A}=\left|\mathbf{r}_{\mathbf{i}}-\mathbf{R}_{\mathbf{A}}\right|$ e $R_{A B}=\mid$ $\mathbf{R}_{\mathbf{A}}-\mathbf{R}_{\mathrm{B}} \mid$ são posições relativas entre elétron-elétron, elétron-núcleo e núcleo-núcleo. $\nabla_{i}^{2}$ e $\nabla_{A}^{2}$ envolvem diferenciação em relação as coordenadas do i-ésimo elétron e do A-ésimo núcleo.

O ponto de partida da aproximação de BO consiste em admitir a existência de uma solução para a equação (2.1), com o hamiltoniano total (2.2), na forma

$$
\Psi(\mathbf{r}, \mathbf{R})=\Phi_{N}(\mathbf{R}) \Phi_{\text {ele }}(\mathbf{r} ; \mathbf{R})
$$

A hipótese adicional, de que o operador de energia cinética nuclear $T_{N}$ não age sobre a função de onda eletrônica, permite separar a equação original em duas equações, uma para os elétrons e outra para os núcleos.

O hamiltoniano eletrônico resultante desta aproximação,

$$
\mathcal{H}_{\text {ele }}=-\sum_{i=1}^{N} \frac{1}{2} \nabla_{i}^{2}-\sum_{i=1}^{N} \sum_{A=1}^{M} \frac{Z_{A}}{r_{i A}}+\sum_{i=1}^{N} \sum_{j>i}^{N} \frac{1}{r_{i j}},
$$


descreve o movimento de $\mathrm{N}$ elétrons em um potencial gerado pelas $\mathrm{M}$ cargas nucleares. A solução da equação de Schrödinger eletrônica $\Phi_{\text {ele }}(\mathbf{r} ; \mathbf{R})$ é uma função explícita das coordenadas eletrônicas $\mathbf{r}=\left(\left\{\mathbf{r}_{\mathbf{i}}\right\}\right)$ e depende parametricamente das coordenadas nucleares $\mathbf{R}=\left(\left\{\mathbf{R}_{\mathbf{A}}\right\}\right)$, o que significa que a cada conjunto de posições nucleares existe um novo problema, cuja solução tem energia $\mathcal{E}_{\text {ele }}=\mathcal{E}_{\text {ele }}(\mathbf{R})$.

Para uma dada configuração de núcleos fixos isto resulta em uma energia total igual a

$$
\mathcal{E}_{\text {total }}=\mathcal{E}_{\text {ele }}(\mathbf{R})+\sum_{A=1}^{M} \sum_{B>A}^{M} \frac{Z_{A} Z_{B}}{R_{A B}} .
$$

A energia total pode ser reinterpretada como uma superfície de energia potencial sobre a qual os núcleos se movem e, uma vez encontrada a solução eletrônica, o problema nuclear pode ser resolvido usando a equação

$$
\mathcal{H}_{N}=T_{N}+\mathcal{E}_{\text {total }}(\mathbf{R})
$$

que descreve as vibrações, rotações e translação molecular.

A aproximação de BO possibilita focar o problema a ser resolvido em, dada uma configuração nuclear, encontrar uma solução para o problema eletrônico. Ainda assim uma solução analítica em geral não é conhecida e mais aproximações são necessárias. Um dos procedimentos mais conhecidos para a solução do problema eletrônico é a aproximação de Hartree-Fock (HF), assunto da próxima seção. É um dos métodos mais populares no estudo da estrutura eletrônica, pois além de fornecer uma solução aproximada para o problema de muitos elétrons, serve de ponto de partida de métodos mais acurados.

\subsection{O Método de Hartree-Fock}

Na mecânica quântica, o estado de uma partícula é dado por um vetor de estado (ou função de onda, na representação de Schrödinger) em um espaço de Hilbert. É 
conveniente considerar funções de onda de um elétron escritas como o produto de uma função da posição $\psi_{i}(\mathbf{r})$, chamada de orbital molecular, por uma função associada ao spin eletrônico. Como elétrons são férmions de spin $s=1 / 2$, dois estados de spin são possíveis, e estes são designados em geral por $\alpha(s)$ e $\beta(s)$. São formados desta forma, para um conjunto de $K$ orbitais moleculares, $2 K$ spin-orbitais moleculares

$$
\chi_{2 i-1}(\mathbf{x})=\psi_{i}(\mathbf{r}) \alpha(s) \quad \text { ou } \quad \chi_{2 i}(\mathbf{x})=\psi_{i}(\mathbf{r}) \beta(s) \quad i=1,2, \ldots, K .
$$

Estados de muitas partículas são representados por vetores no espaço produto dos espaços lineares das partículas individuais. O princípio de indistinguibilidade de sistemas fermiônicos exige que a função total que descreva o sistema seja antissimétrica em relação à troca de posição entre dois destes elétrons. Designando por $\left\{\chi_{i}\left(\mathbf{x}_{1}\right)\right\}$, $\left\{\chi_{j}\left(\mathbf{x}_{2}\right)\right\}, \ldots,\left\{\chi_{k}\left(\mathbf{x}_{N}\right\}\right.$ bases ortonormais discretas definidas em cada um dos espaços de 1 partícula, a função de onda de $\mathrm{N}$ elétrons pode ser escrita na forma de um determinante,

$$
\Psi\left(\mathbf{x}_{1}, \mathbf{x}_{2}, \ldots, \mathbf{x}_{N}\right)=\frac{1}{\sqrt{N !}}\left|\begin{array}{cccc}
\chi_{i}\left(\mathbf{x}_{1}\right) & \chi_{j}\left(\mathbf{x}_{1}\right) & \cdots & \chi_{k}\left(\mathbf{x}_{1}\right) \\
\chi_{i}\left(\mathbf{x}_{2}\right) & \chi_{j}\left(\mathbf{x}_{2}\right) & \cdots & \chi_{k}\left(\mathbf{x}_{2}\right) \\
\vdots & \vdots & \vdots & \\
\chi_{i}\left(\mathbf{x}_{N}\right) & \chi_{j}\left(\mathbf{x}_{N}\right) & \cdots & \chi_{k}\left(\mathbf{x}_{N}\right)
\end{array}\right|
$$

conhecido como determinante de Slater.

É conveniente introduzir uma notação mais compacta, que consiste em explicitar apenas os termos da diagonal, suprimindo a constante de normalização e mantendo índices dos elétrons na ordem $\left(\mathbf{x}_{1}, \mathbf{x}_{2}, \ldots, \mathbf{x}_{N}\right)$, ou seja,

$$
\Psi=(1 / N !)^{-1 / 2} \operatorname{det}\left\{\chi_{i} \chi_{j} \cdots \chi_{k}\right\}=\| \chi_{i} \chi_{j} \cdots \chi_{k}|\rangle
$$

Os índices $i, j$ e $k$ indexam estados de 1 elétron. Assim, dado um conjunto finito de $2 K>N$ spin-orbitais $(i, j, k=1,2, \ldots, K)$ uma quantidade enorme de determinantes 
podem ser construídos, dada pelo coeficiente binomial

$$
\left(\begin{array}{c}
2 K \\
N
\end{array}\right)=\frac{(2 K !)}{N !(2 K-N) !} .
$$

O método de HF consiste em, primeiramente, tomar como função de onda um único determinante de Slater,

$$
\left|\Psi_{0}\right\rangle=|| \chi_{1} \chi_{2} \cdots \chi_{N}|\rangle
$$

a mais simples função antissimétrica que pode ser usada para descrever o problema de N elétrons. Nesta aproximação, a energia eletrônica

$$
E_{0}=\left\langle\Psi_{0}|\mathcal{H}| \Psi_{0}\right\rangle
$$

onde $\mathcal{H}$ é o hamiltoniano eletrônico (2.4), pode ser escrita explicitamente em termos dos spin-orbitais como sendo igual a

$$
E_{0}=\sum_{a=1}^{N}\langle a|h| a\rangle+\frac{1}{2} \sum_{a=1}^{N} \sum_{b=1}^{N}(\langle a b \mid a b\rangle-\langle a b \mid b a\rangle) .
$$

$\mathrm{Na}$ equação acima, $h$ é chamado hamiltoniano de caroço

$$
h(1)=-\frac{1}{2} \nabla_{1}^{2}-\sum_{A=1}^{M} \frac{Z_{A}}{r_{1 A}}
$$

e foram ainda introduzidas as seguintes notações

$$
\begin{aligned}
\langle a|h| a\rangle & =\left\langle\chi_{a}(1)|h(1)| \chi_{a}(1)\right\rangle \\
\langle a b \mid c d\rangle & =\left\langle\chi_{a}(1) \chi_{b}(2)\left|\frac{1}{r_{12}}\right| \chi_{c}(1) \chi_{d}(2)\right\rangle
\end{aligned}
$$

para integrais de 1 e 2 elétrons.

O passo seguinte consiste em usar um procedimento variacional para encontrar o conjunto de spin-orbitais que minimizam a energia eletrônica. Este procedimento é realizado variando os bras $\delta\left\langle\chi_{a}\right|$ e introduzindo $N^{2}$ multiplicadores de Lagrange $\varepsilon_{b a}$ para ter em conta a condição de normalização

$$
\left\langle\chi_{a} \mid \chi_{b}\right\rangle=\delta_{a b}
$$


Da condição de extremo variacional

$$
\delta\left(\left\langle\Psi_{0}|\mathcal{H}| \Psi_{0}\right\rangle-\sum_{a b} \varepsilon_{a b}\left(\left\langle\chi_{a} \mid \chi_{b}\right\rangle-\delta_{a b}\right)\right)=0
$$

resultam um conjunto de equações, denominadas equações de Hartree-Fock [18]

$$
f(1)\left|\chi_{a}\right\rangle=\sum_{b} \varepsilon_{b a}\left|\chi_{a}\right\rangle
$$

O conjunto $\left\{\varepsilon_{a b}\right\}$ forma uma matriz simétrica real que sempre pode ser diagonalizada. A invariância da equação de Fock sob transformações unitárias permite colocá-las na forma usual de uma equação de autovalores,

$$
f(1)\left|\chi_{a}(1)\right\rangle=\varepsilon_{a}\left|\chi_{a}(1)\right\rangle \quad a=1,2 \ldots N
$$

conhecida como equação canônica de Hartree-Fock. Nesta expressão observa-se que $\varepsilon_{a}$ tem a interpretação física de energia do spin-orbital $\chi_{a}$ e $f(i)$ é um operador efetivo de um elétron chamado operador de Fock. A forma explícita deste operador na realidade envolve a soma de vários outros operadores,

$$
f(1)=h(1)+\sum_{b}\left(\mathcal{J}_{b}(1)-\mathcal{K}_{b}(1)\right)
$$

$\mathcal{J}_{b}(1)$ e $\mathcal{K}_{b}(1)$ são conhecidos como os operadores de Coulomb e Exchange, respectivamente, e dão conta dos efeitos de interação coulombiana e de troca entre os elétrons. São operadores integrais definidos por sua aplicação em $\left|\chi_{a}\right\rangle$ como sendo iguais a

$$
\begin{aligned}
\mathcal{J}_{b}(1)\left|\chi_{a}(1)\right\rangle & =\left[\int \chi_{b}^{*}(2) \frac{1}{r_{12}} \chi_{b}(2) d \mathbf{x}_{2}\right]\left|\chi_{a}(1)\right\rangle \\
\mathcal{K}_{b}(1)\left|\chi_{a}(1)\right\rangle & =\left[\int \chi_{b}^{*}(2) \frac{1}{r_{12}} \chi_{a}(2) d \mathbf{x}_{2}\right]\left|\chi_{b}(1)\right\rangle .
\end{aligned}
$$

Nas equações de HF, o problema de encontrar a solução do problema de N elétrons fica reduzido a solucionar $N$ problemas de 1 elétron. Entretanto, o problema agora é não linear, pois o operador de Fock para o i-ésimo elétron depende explicitamente dos spin-orbitais dos outros $N-1$ elétrons. O problema é em geral resolvido 
por um procedimento iterativo, denominado auto consistente ou SCF (Self-ConsistentField). Nesta abordagem, um conjunto arbitrário de spin-orbitais é usado para construir o operador de fock. As equações de HF são então resolvidas para obter um novo conjunto de spin-orbitais, que são usados para construir um novo operador de Fock e o processo é repetido até que um critério de convergência pré-estabelecido seja alcançado.

No caso de sistemas de camada fechada onde cada orbital molecular está ocupado com dois elétrons, existe um desenvolvimento adicional, conhecido como Hartree-Fock restrito (RHF), que modifica a expressão do operador de Fock, levando à expressões em termos dos orbitais moleculares,

$$
\left[h\left(\mathbf{r}_{1}\right)+\sum_{b=1}^{N / 2}\left(2 \mathcal{J}_{b}\left(\mathbf{r}_{1}\right)-\mathcal{K}_{b}\left(\mathbf{r}_{1}\right)\right)\right]\left|\psi_{a}\right\rangle=\varepsilon_{a}\left|\psi_{a}\right\rangle .
$$

A expressão para energia eletrônica também é modificada para

$$
E_{0}=2 \sum_{a=1}^{N / 2} \mathrm{~h}_{a a}+\sum_{a, b=1}^{N / 2}\left(2 \mathcal{J}_{a b}-\mathcal{K}_{a b}\right)
$$

onde $\mathrm{h}_{a a}=\sum_{a=1}^{N / 2}\langle a|h| a\rangle, \mathcal{J}_{a b}=\langle a b \mid b a\rangle$ e $\mathcal{K}_{a b}=\langle a b \mid b a\rangle$.

Procedimentos numéricos para resolver as equações de HF existem apenas no caso de sistemas atômicos. Para sistemas moleculares, no entanto, o problema tornase computacionalmente bem mais complexo e a técnica proposta ainda na década de 50, conhecida como método de Hartree-Fock-Roothaan, é usada para resolver as resolvê-las.

\subsubsection{O método de Hartree-Fock-Roothaan}

O método de Roothaan para resolver as equações de HF consiste em utilizar uma expansão dos orbitais moleculares em uma base finita conhecida, transformando o problema em uma equação algébrica que pode ser resolvida por procedimentos usuais 
de diagonalização matricial. Introduzindo um conjunto $\left\{\phi_{\nu}(\mathbf{r})\right\}$ de $\mathrm{K}$ funções base e escrevendo a expansão como sendo igual a

$$
\psi_{\nu}(\mathbf{r})=\sum_{\nu=1}^{K} C_{\nu i} \phi_{\nu}(\mathbf{r}) \quad i=1,2, \ldots, K
$$

a equação

$$
f(1) \psi_{i}(1)=\varepsilon_{i} \psi_{i}(1)
$$

é transformada em equações para os coeficientes,

$$
f(1) \sum_{\nu=1}^{K} C_{\nu i} \phi_{\nu}(1)=\varepsilon_{i} \sum_{\nu=1}^{K} C_{\nu i} \phi_{\nu}(1), \quad i=1,2, \ldots, K
$$

conhecidas como equações de Roothaan. Multiplicando à esquerda por $\left\langle\phi_{\mu}\right|$ elas podem na forma matricial,

$$
\mathrm{FC}=\mathrm{SC} \varepsilon
$$

com a introdução das matrizes de overlap $S_{\mu \nu}=\left\langle\phi_{\mu} \mid \phi_{\nu}\right\rangle$ e de fock $F_{\mu \nu}=\left\langle\phi_{\mu}|f| \phi_{\nu}\right\rangle$, além matriz $\varepsilon_{i j}=\varepsilon_{i} \delta_{i j}$ e da matriz dos coeficientes, cujos elementos são os $C_{\nu i}$.

O operador de Fock escrito na forma matricial, pode ser separado em duas partes, o hamiltoniano de caroço $H_{\mu \nu}$ e a parte de 2 elétrons $G_{\mu \nu}$,

$$
F_{\mu \nu}=\underbrace{\left\langle\phi_{\mu}|h(1)| \phi_{\nu}\right\rangle}_{H_{\mu \nu}}+\underbrace{\sum_{\lambda, \sigma} P_{\sigma \lambda}\left[\langle\mu \lambda \mid \nu \sigma\rangle-\frac{1}{2}\langle\mu \lambda \mid \sigma \nu\rangle\right]}_{G_{\mu \nu}},
$$

onde

$$
P_{\mu \nu}=2 \sum_{a} C_{\mu a} C_{\nu a}^{*}
$$

é chamada de matriz densidade do sistema.

A energia eletrônica pode ser obtida usando o formalismo matricial pela expressão

$$
E=\frac{1}{2} \sum_{\lambda, \sigma} P_{\sigma \lambda}\left(H_{\lambda \sigma}+F_{\sigma \lambda}\right)=\frac{1}{2} \operatorname{Tr}[\mathbf{P}(\mathbf{H}+\mathbf{F})] .
$$




\subsection{Funções Base}

Em princípio, a representação exata de um orbital molecular exige um número infinito de funções base, o que na prática é irrealizável. Desta forma, um erro inerente ao procedimento de expansão é erro de truncamento da base, definido como a diferença entre a energia obtida no limite HF e a energia calculada usando o procedimento HF-SCF. A escolha de uma base adequada para a expansão visa estabelecer um compromisso entre eficiência computacional e qualidade dos resultados. Para manter este compromisso, três aspectos básicos são respeitados: buscar um número reduzido de funções base, diminuindo assim o número de integrais de 2 elétrons a serem calculadas; escolher formas funcionais para estas funções base que minimizem os esforços computacionais para o cálculo de cada integral; obter um erro pequeno de truncamento.

Dois tipos básicos de conjunto de funções base [19] (também chamados de orbitais atômicos) obedecem a estas regras e são amplamente utilizadas nos cálculos de estrutura eletrônica: funções do tipo Slater STO (Slater-type Orbital) [20] e funções do tipo gaussianas GTO (Gaussian-type Orbital) [21] .

As STOs têm a forma

$$
\phi_{\zeta, n, l, m}(r, \theta, \varphi)=N Y_{l, m}(\theta, \varphi) r^{n-1} e^{-\zeta r},
$$

onde $N$ é uma constante de normalização e os $Y_{l m}$ são harmônicos esféricos. A principal característica destes orbitais é o decaimento exponencial, espelhado no comportamento da solução exata da equação de Schrödinger para um átomo hidrogenóide, que favorece a rápida convergência dos resultados usando um número reduzido de funções base. Entretanto, a desvantagem das STOs é que integrais de 1 e 2 elétrons na maior parte dos casos não possuem solução analítica e seus cálculos numéricos demandam grande esforço computacional. 
A alternativa às STOs são as GTOs, que possuem a seguinte forma funcional

$$
\phi_{\zeta, n, l, m}(r, \theta, \varphi)=N Y_{l, m}(\theta, \varphi) r^{2 n-2-l} e^{-\zeta r^{2}},
$$

em coordenadas esféricas. Elas também podem ser escritas em coordenadas cartesianas,

$$
\phi_{\zeta, l_{x}, l_{y}, l_{z}}(x, y, z)=N x^{l_{x}} y^{l_{y}} z^{l_{z}} e^{-\zeta r^{2}},
$$

de forma que a soma de $l_{x}, l_{y}$ e $l_{z}$ permite classificar o tipo de orbital. Quando $l_{x}=l_{y}=l_{z}=0$ o orbital é uma gaussiana tipo s; quando $l_{x}+l_{y}+l_{z}=1$, gaussiana tipo p; quando $l_{x}+l_{y}+l_{z}=2$, gaussiana tipo d; e assim por diante.

A facilidade no cálculo das integrais envolvendo produtos de GTOs é a principal vantagem deste tipo de base. A desvantagem é que o decaimento gaussiano não reproduz adequadamente as características dos orbitais atômicos à curtas e nem à longas distâncias, o que torna neste aspecto este tipo de função base inferior às STOs. Para contornar este problema, em geral um pacote de funções gaussianas é usado para representar um orbital molecular, conhecido como função gaussiana contraída. Cada função base contraída $\varphi_{i}$, é construída como uma combinação linear

$$
\phi_{i}=\sum_{i=1}^{L} d_{j i} g_{j}
$$

de outras funções, chamadas de gaussianas primitivas. Elas são representadas por $g_{j}$, têm a forma gaussiana dada pela equação (2.33) e são centradas no mesmo núcleo atômico. As GTOs são usadas na maioria dos cálculos de estrutura eletrônica, já que a eficiência computacional no cálculos das integrais é bem maior que no caso das STOs. Existe na literatura, uma quantidade muito grande deste tipo de funções base, desenvolvidas especialmente para o cálculo das mais variadas propriedades [22].

Uma vez decidida a forma das funções base (GTO ou STO), resta ainda a escolha prática do número de funções base a ser para representar cada orbital atômico. A 
escolha mais simples é conhecida como a base minima, onde apenas uma função contraída é usada para representar cada orbital. Por exemplo, se usa uma única função base no caso de um átomo de de $\mathrm{H}$ ou He (orbitais 1s); 5 funções base no caso de átomos de Li a Ne (1 orbital 1s, 1 orbital 2s, e 3 orbitais 2 p); e assim por diante. Esta simplificação em geral é insatisfatória para a obtenção de resultados acurados e uma melhora significativa nos resultados é conseguida aumentando-se o número de funções base para cada orbital. Bases DZ (double-zeta) usam duas, TZ (triple-zeta) usam três, e assim por diante.

As funções base do tipo SV(split-valence) buscam um compromisso intermediário entre a inadequação das base mínima e o alto custo computacional das funções $D Z$ ou $T Z$, atribuindo a base mínima para os orbitais de caroço e bases duplas para os orbitais de valência. Jonh Pople criou série de funções deste tipo, designadas genericamente por $X$-YZG (3-21G, 6-31G, etc), onde $X$ designa o número de funções primitivas usadas para ajustar os orbitais de caroço e os números restantes $Y Z$ significam que a região de valência é dividida em duas partes com Y primitivas na primeira $\mathrm{Z}$ na segunda.

Nesta categoria melhorias ainda podem ser realizadas com a inclusão de funções adicionais de polarização e funções difusas. Funções de polarização melhoram a descrição da deformação dos orbitais que participam da ligação. A existência de um asterisco $(*)$ - ou "(d)" — logo após a letra G, como em 6-31G* — ou 6-31G(d) — indica que funções $d$ foram adicionadas aos átomos pesados (não hidrogênio). Dois asteriscos $\left({ }^{*}\right)$ indicam que funções $p$ também foram adicionadas aos átomos de hidrogênio. Funções difusas, que neste esquema são representadas por sinal de adição $(+)$, melhoram a descrição da densidade eletrônica em regiões relativamente afastadas do núcleo.

Dunnning e Huzinaga desenvolveram o conjunto conhecido como cc-PVXZ (correlation-consistent $X$ Zeta, onde $X=D$ (double), $T$ (triple), Q (quadruple), 5, 6, .. etc, e os coeficientes são otimizados para cálculos que exijam correlação eletrônica, in- 
cluindo naturalmente funções de polarização. $V X Z$ indica que $X$ funções são usadas, mas apenas para os orbitais de valência. Funções difusas a todos os átomos em geral também são adicionadas, indicadas pelo prefixo " $a u g$ ", como em aug-cc-PVDZ.

Ainda que uma base infinita fosse usada, atingindo o limite HF, a solução não seria igual à solução exata. Ao tratar a interação eletrônica de uma forma média, o método de HF ignora interações instantâneas. Os efeitos ignorados pelo método de HF são conhecidos como correlação eletrônica e tratar estes efeitos corretamente constituem o principal desafio atual nos métodos de estrutura eletrônica.

\subsection{Correlação eletrônica}

Os estados estacionários de um elétron em um sistema molecular, na aproximação de HF, são estados estacionários do operador de Fock,

$$
f(i)=h(i)+v^{H F}(i) ; \quad v^{H F}(i)=\sum_{b}\left(\mathcal{J}_{b}(i)-\mathcal{K}_{b}(i)\right)
$$

que pode ser interpretado como um hamiltoniano efetivo para um único elétron $i$ movendo-se no campo gerado pelo potencial nuclear (contido em $h$ ) juntamente com um potencial médio $v^{H F}(i)$ de coulomb-troca devido à existência dos outros elétrons.

A aproximação de HF pode ser formalmente interpretada como um modelo de partícula independente, isto é, que não contém interações eletrônicas (operadores de dois corpos), com o hamiltoniano total dado pela soma de operadores de Fock

$$
H_{H F}=\sum_{i=1}^{N} f(i) .
$$

É importante notar que interações coulombianas de dois corpos (repulsão eletrônica) que dão origem às correlações dinâmicas entre os elétrons não podem ser descrita por um potencial de um corpo como $v^{H F}(i)$ e pode-se esperar apenas que propriedades que não dependam destas correlações de forma essencial possam ser bem descritas 
por este potencial. A utilidade do tratamento HF vem do fato de que propriedades importantes sobrevivem ao truncamento da correlação. Tipicamente energia de HF corresponda a até $99 \%$ da energia exata do sistema [19].

Além disto, ainda que o método de HF não permita obter a solução exata do problema, ele serve como referência para a energia de correlação do sistema e é um ponto de partida para métodos mais acurados. A solução do problema de HF permite a construção de uma base para a expansão da soluções exata do problema.

O operador de Fock depende de $\mathrm{N}$ spin-orbitais. Uma vez que estes tenham sido determinados, no entanto, ele é um operador hermitiano bem definido, o que significa que possui um número infinito de autofunções. Os $\mathrm{N}$ orbitais de mais baixa energia, $\left\{\chi_{1}, \ldots, \chi_{a}, \chi_{b}, \ldots, \chi_{N}\right\}$, são chamados de orbitais ocupados os restantes, $\left\{\chi_{N+1}, \ldots\right.$, $\left.\chi_{r}, \chi_{s}, \ldots\right\}$, de orbitais virtuais. O determinante de Slater composto pelos $\mathrm{N}$ orbitais ocupados corresponde ao estado fundamental na aproximação de HF,

$$
\left|\Psi_{0}\right\rangle=\| \chi_{1}, \ldots, \chi_{a}, \chi_{b}, \ldots, \chi_{N}|\rangle
$$

Um determinante é dito mono-excitado quando um elétron, antes ocupando $\chi_{a}$ é promovido a um spin-orbital virtual $\chi_{r}$, e é designado por

$$
\left|\Psi_{a}^{r}\right\rangle=\| \chi_{1}, \ldots, \chi_{r}, \chi_{b}, \ldots, \chi_{N}|\rangle
$$

Do mesmo modo, um determinante é dito duplamente excitado quando dois elétrons, antes ocupando $\xi_{a}$ e $\xi_{b}$ são promovidos aos orbitais virtais $\xi_{r}$ e $\xi_{s}$, respectivamente. São designados por

$$
\left|\Psi_{a b}^{r s}\right\rangle=\| \chi_{1}, \ldots, \chi_{r}, \chi_{s}, \ldots, \chi_{N}|\rangle
$$

Todos os $\left(\begin{array}{c}2 K \\ N\end{array}\right)$ determinantes, portanto, podem classificados desta forma (como estados fundamental, mono, duplamente, triplamente, .., $N$-uplamente excitados). O conjunto infinito de determinantes eletrônicos $\left\{\left|\Psi_{i}\right\rangle\right\}=\left\{\left|\Psi_{0}\right\rangle,\left|\Psi_{a}^{r}\right\rangle,\left|\Psi_{a b}^{r s}\right\rangle,\left|\Psi_{a b c}^{r s t}\right\rangle\right.$, 
...\} formam uma base que permite representar a solução exata do hamiltoniano eletrônico

$$
\left|\Phi_{e l e}\right\rangle=\left|\Psi_{0}\right\rangle+\sum_{a, r} C_{a}^{r}\left|\Psi_{a}^{r}\right\rangle+\sum_{a, b, r, s} C_{a b}^{r s}\left|\Psi_{a b}^{r s}\right\rangle+\sum_{a, b, c, r, s, t} C_{a b c}^{r s t}\left|\Psi_{a b c}^{r s t}\right\rangle+\cdots
$$

A energia exata do problema eletrônico são os autovalores da matriz $\left\langle\Psi_{i}|\mathcal{H}| \Psi_{j}\right\rangle$ da representação do operador Hamiltoniano na base $\left\{\left|\Psi_{i}\right\rangle\right\}$. Como todos os determinantes são obtidos a partir de uma configuração de spin-orbitais, este procedimento é conhecido como Configuração de Interação (CI). O menor autovalor desta matriz, denotado por $E_{e x}$, é a energia exata não relativística para o estado fundamental. A diferença entre $E_{e x}$ e a energia e a energia no limite HF, $E_{0}$, é chamada energia de correlação

$$
E_{\text {corr }}=E_{\text {ex }}-E_{0} \text {. }
$$

Em termos práticos, uma base finita de determinantes é usada, construída a partir de um conjunto finito de $2 K$ spin-orbitais. Este procedimento (conhecido como full- $C I$ ) leva à solução exata dentro do subespaço gerado pelos $\left(\begin{array}{c}2 K \\ N\end{array}\right)$ determinantes. Mesmo usando bases mínimas o número de determinantes é absurdamente grande. Para um conjunto de 10 elétrons 20 funções base, por exemplo, o número de determinantes é da ordem de $10^{8}$ !.

Além disso, uma das sérias deficiências nos cálculos CI é o problema de extensividade, quando a base é truncada. Um método é extensivo quando a energia é proporcional ao número $N$ de elétrons. Para ilustrar melhor este conceito, considere um dímero formado por dois monômeros não interagentes (separados por uma distância infinita, por exemplo). Em métodos extensivos, a energia calculada para o dímero é igual a soma da energia dos monômeros individuais, calculada usando o mesmo método.

Desta forma, embora conceitualmente simples, o método CI é de difícil implemen- 
tação computacional. Neste sentido, o uso de métodos perturbativos é uma alternativa poderosa, já que satisfazem naturalmente o critério de extensividade.

\subsection{Aproximações perturbativas}

Os métodos de aproximação em mecânica quântica podem ser separados em dois grandes grupos, geralmente chamados métodos perturbativos e métodos nãoperturbativos. O subgrupo mais importante dos métodos não-perturbativos é o dos métodos variacionais, ao qual pertence o método CI. Métodos variacionais permitem ter um controle sobre a energia do sistema, no sentido que é sabido a priori que ela está sempre acima a energia exata do problema. A falta de extensividade é uma de suas sérias limitações.

Na teoria de pertubação independente do tempo, o hamiltoniano do problema é separado em duas partes

$$
H=H_{0}+\mathcal{V},
$$

e supôe-se conhecida do problema solução do problema

$$
H_{0}\left|\phi_{0}^{(0)}\right\rangle=E_{0}^{(0)}\left|\phi_{0}^{(0)}\right\rangle
$$

referente ao hamiltoniano não perturbado $H_{0}$.

Um procedimento sistemático de expansão em série de potências é desenvolvido em seguida para aproximar as soluções de

$$
\left(H_{0}+\lambda \mathcal{V}\right)\left|\phi_{0}\right\rangle=E_{0}\left|\phi_{0}\right\rangle
$$

em termos dos autovalores $E_{n}^{(0)}$ e autovetores de $H_{0}$.

A expansão de uso mais frequente é conhecida como Teoria de Perturbação de Rayleigh-Schrödinger (RSPT), onde são usadas expansões para $\left|\phi^{(0)}\right\rangle$ e $E_{n}^{(0)}$ na forma

$$
\begin{array}{r}
E_{0}=E_{0}^{(0)}+\lambda E_{0}^{(1)}+\lambda^{2} E_{0}^{(2)}+\cdots \\
\left|\phi_{0}\right\rangle=\left|\phi_{0}^{(0)}\right\rangle+\lambda\left|\phi_{0}^{(1)}\right\rangle+\lambda^{2}\left|\phi_{n}^{(2)}\right\rangle+\cdots
\end{array}
$$


As correções perturbativas, ordem a ordem, podem ser obtidas substituindo esta decomposição na equação de autovalores (2.44) e igualando-se os termos ordem a ordem, adotando ainda a condição de normalização intermediária,

$$
\left\langle\phi_{0}^{(0)} \mid \phi_{0}\right\rangle=1
$$

Desta forma chega-se a expressão para as correções em cada uma das ordens,

$$
\begin{aligned}
E_{0}^{(0)} & =\left\langle\phi_{0}^{(0)}\left|H_{0}\right| \phi_{0}^{(0)}\right\rangle \\
E_{0}^{(1)} & =\left\langle\phi_{0}^{(0)}|\mathcal{V}| \phi_{0}^{(0)}\right\rangle \\
E_{0}^{(2)} & =\left\langle\phi_{0}^{(0)}|\mathcal{V}| \phi_{0}^{(1)}\right\rangle \\
& \vdots \\
E_{0}^{(n)} & =\left\langle\phi_{0}^{(0)}|\mathcal{V}| \phi_{0}^{(n-1)}\right\rangle .
\end{aligned}
$$

As expressões acima ainda podem ser modificadas de tal forma que a função de onda de ordem $n$ permita obter a correção de ordem $2 n+1$ (este fato é conhecido como teorema $2 n+1$ e mais detalhes podem ser encontrados na referência [17]). Entretanto, nem sempre é possível obter uma solução exata para as equações diferenciais que determinam as funções perturbadas $\left|\phi_{0}^{(n)}\right\rangle,(n=1,2, \ldots)$. Por esta razão, é comum expandir estas funções na base das funções de ordem zero, $\left|\phi_{0}^{(0)}\right\rangle$. Os coeficientes de expansão são determinados pela equação mesma equação de autovalores (2.44). A correção de segunda ordem, por exemplo, pode ser escrita como

$$
E_{0}^{(2)}=\sum_{n \neq 0} \frac{\left|\left\langle\phi_{0}^{(0)}|\mathcal{V}| \phi_{n}^{(0)}\right\rangle\right|^{2}}{E_{0}^{(0)}-E_{n}^{(0)}}
$$

A partição do hamiltoniano usada na busca da energia de correlação, proposta em 1934 por C. Møller e M.S. Plesset, é conhecida como MPPT (Møller Plesset Perturbation Theory). Nesta aproximação, o hamiltoniano não perturbado é dado pela 
soma dos operadores de Fock,

$$
H_{0}=H_{H F}=\sum_{i=1}^{N} f(i) .
$$

A perturbação $\mathcal{V}$ é então dada pela diferença

$$
\mathcal{V}=\mathcal{H}-H_{H F},
$$

onde $\mathcal{H}$ é o hamiltoniano eletrônico. Com esta escolha, a energia obtida pelo método de HF associada ao determinante do estado fundamental $\left|\Psi_{0}\right\rangle$, dada pelo valor esperado

$$
E_{H F}=\left\langle\Psi_{0}|\mathcal{H}| \Psi_{0}\right\rangle=\left\langle\Psi_{0}\left|H_{0}+\mathcal{V}\right| \Psi_{0}\right\rangle=E_{0}^{(0)}+E_{0}^{(1)},
$$

já inclui naturalmente a correção perturbativa de primeira ordem.

Portanto, a primeira correção perturbativa a ser encontrada é dada pela expressão de segunda ordem

$$
E_{0}^{(2)}=\sum_{J \neq 0} \frac{\left\langle\Psi_{J}|\mathcal{V}| \Psi_{0}\right\rangle\left\langle\Psi_{0}|\mathcal{V}| \Psi_{J}\right\rangle}{E_{0}^{(0)}-E_{J}^{(0)}},
$$

onde $\left|\Psi_{J}\right\rangle$ é um determinante excitado, autofunção de $H_{H F}$ com autovalor $E_{J}^{(0)}$. Na verdade, é possível mostrar que apenas excitações duplas contribuem para o cálculo desta correção [17], que pode ainda ser colocada em função dos orbitais moleculares como sendo igual

$$
E_{0}^{(2)}=\frac{1}{4} \sum_{a, b}^{o c} \sum_{r, s}^{v i r} \frac{|\langle a b|| r s\rangle|^{2}}{\varepsilon_{a}+\varepsilon_{b}-\varepsilon_{r}-\varepsilon_{s}} .
$$

As correções de segunda, terceira, etc. ordem em MPPT são designadas respectivamente por $\operatorname{MPn}(n=1,2, \ldots)$. Expressões algébricas para correções de ondem mais alta (MP3 ou superiores) aumentam razoavelmente em complexidade e técnicas diagramáticas em geral são usadas para obtê-las. Usando estas técnicas Goldstone [23] demonstrou que a MPPT é extensiva em todas as ordens.

Na prática, em geral o uso de correções perturbativas está limitado até no máximo MP5. Quando é necessário ir além, existem meios mais convenientes, como o método 
de Coupled-Cluster (CC) [24]. Vale apena ressaltar, no entanto, que a correção de segunda ordem MP2 em geral já é responsável por 80 - 90\% da energia de correlação [19]. Além disto, a correção perturbativa de segunda ordem para o estado fundamental é sempre negativa, o que a torna bem balanceada, já que energia HF é um limite superior para a energia exata do sistema. Isto já não ocorre com a energia de terceira ordem $M P 3$, que em geral não melhora a descrição do sistema. Para ir além de $M P 2$ é necessário ir até $M P 4$, o que aumenta consideravelmente o custo computacional.

O custo computacional está associado ao tamanho do sistema (número de elétrons) a ser tratado e do número $K$ de funções base usadas na descrição dos orbitais. Formalmente, o custo computacional do método de HF cresce com $K^{4}$, que é o número integrais de 2 elétrons envolvendo estas funções que precisam ser calculadas. Já $M P 2$ tem um custo que depende de $K^{5}$ no cálculo da correção. O método CI, com excitações simples e duplas (CISD) escalam com $K^{6}$, crescendo rapidamente para $K^{10}$ quando se leva a aproximação até excitações quadruplas (CISDTQ). Mais detalhes sobre estes custos computacionais e como reduzi-los podem ser encontrados na referência [19].

Dos métodos discutidos, $M P 2$ se mostra a forma mais econômica de se incluir correlação eletrônica. Em muitos casos este método produz excelentes resultados, sobretudo quando conjuntos de base grandes são usados ( $D Z$ ou $T Z$ ) [25, 26].

\subsection{Aplicações}

Um número muito grande de propriedades eletrônicas podem ser obtidas usando os métodos desenvolvidos neste capítulo. Energias, momento de dipolo, propriedades espectroscópicas (frequências do espectro de absorção, emissão, infravermelho, etc.) são exemplos destas propriedades. Diversos livros textos tratam detalhadamente sobre a forma como obtê-las [17-19, 27-29]. Ilustraremos aqui apenas a forma como cargas parciais podem ser ajustadas nos núcleos atômicos, pois esta aplicação será de utilidade 
quando tratarmos de simulação computacional.

\subsubsection{Análise de população e a metodologia CHELPG}

Os métodos de análise da população podem ser separados entre aqueles baseados na função de onda, na densidade eletrônica e os que usam ajustes de cargas do potencial eletrostático. A esta última categoria pertence a metodologia CHELPG ( CHarges from ELectrostatic Potentials using a Grid), criada por Breneman e Wiberg [30], que é usada para ajustar as cargas atômicas sobre os sítios atômicos. Estas cargas são amplamente utilizadas como parâmetros no potencial clássico intermolecular de simulações computacionais.

Este procedimento consiste em, primeiramente, criar uma rede retangular de pontos ao redor da molécula de interesse, excluindo pontos que estejam no interior das esferas de van der Waals. O potencial eletrostático em cada um destes pontos é calculado em seguida. Finalmente, este potencial gerado é usado para ajustar as cargas centradas nos núcleos atômicos. 


\section{Capítulo 3}

\section{Metodologia teórica: moléculas em solução}

A complexidade dos fenômenos físico-químicos em solução tornou necessário o desenvolvimento de uma ampla variedade de modelos teóricos e técnicas computacionais para representar moléculas em solução. Uma área de especial atenção, onde uma ampla variedade de técnicas foram desenvolvidas nos últimos anos é o estudo de efeitos de solvente em moléculas e biomoléculas. Neste capítulo, apresentamos os principais modelos usados neste trabalho no estudo das moléculas em solução.

\subsection{Energia livre de solvatação}

O solvente é tradicionalmente definido como um líquido no qual outra substância pode ser dissolvida e do qual esta mesma substância pode ser recuperada sem alterações [31]. A água é, sem dúvida, o mais importante solvente, sobretudo em sistemas biológicos, já que é o mais abundante componente dos organismos vivos. Ela tem uma estrutura complexa, devido à sua capacidade de realizar associações denominadas ligações de hidrogênio, e possui diversas propriedades anômalas que desafiam modelos teóricos. Um detalhado conhecimento do efeito do meio é essencial para o entendimento dos princípios que regem os sistemas biológicos. O efeito de solvente ainda tem 
fundamental importância em diversos outros processos, como propriedades eletrônicas, espectroscópicas e reativas [31.

A solvatação de um soluto pode ser definida [32,33] como o processo no qual uma partícula do soluto é transferida de uma posição fixa na fase gasosa para uma posição fixa em solução, à temperatura, pressão e composição do solvente constantes. A energia livre de solvatação $\Delta G_{\text {solv }}$ é definida como o trabalho reversível neste processo. De acordo com esta definição, ela agrega contribuições relacionadas as interações solutosolvente, bem como contribuições devido a mudanças internas no soluto (e no solvente) ocorridas após a solvatação.

A energia livre de solvatação é em geral calculada como a soma de contribuições. Neste trabalho, as contribuições foram separadas em eletrostáticas $\left(\Delta G_{e l}\right)$ e não eletrostáticas $\left(\Delta G_{n e l}\right)$. A contribuição eletrostática mede o trabalho gasto na construção da distribuição de carga do soluto em solução e possui duas componentes: (i) o trabalho necessário para criar a distribuição de carga de fase gasosa do soluto em solução e (ii) o trabalho necessário para o solvente polarizar a distribuição de cargas do soluto. Já a contribuição não eletrostática está relacionada a dois passos. O primeiro passo consiste em formar uma cavidade grande o suficiente para acomodar o soluto e está acompanhada de um quebra das ligações coesivas entre as moléculas de solvente, de modo que esta contribuição (chamada de cavitação) é em geral desfavorável para o processo de solvatação $\left(\Delta G_{c a v}>0\right)$. No segundo passo forças de van der Waals entre soluto e solvente são criadas. Estas forças são aplicadas tanto para o soluto quanto para o solvente e contribuem favoravelmente $\left(\Delta G_{v W}<0\right)$ para o processo de solvatação.

A energia livre de solvatação é usada como uma medida da capacidade de associação entre as moléculas e da espontaneidade do processo de solvatação. Grandes progressos foram realizados no desenvolvimento de modelos baseados em simulação computacional de dinâmica molecular e Monte Carlo. Duas abordagens se destacam: 
o método de Perturbação de Energia Livre ou FEP (Free-Energy Perturbation) e o método de Integração Termodinâmica [34]. Outra abordagem bastante utilizada é o uso de modelos contínuos [35], que podem usar tanto modelos clássicos quanto cálculos quânticos $a b$ initio.

\subsubsection{Os modelos contínuos}

Modelos contínuos são tradicionalmente baseados em efeitos eletrostáticos. O solvente é caracterizado como um meio contínuo, em geral homogêneo e isotrópico, caracterizado pela constante dielétrica $\epsilon$. Estes modelos foram desenvolvidos inicialmente por Born [36], Onsager [37] e Kirkwood [38], ainda na década de 1930 e têm sido usados e desenvolvidos até hoje. Eles permitem tratar de modo acurado as forças eletrostáticas de longo alcance, essenciais para a compreensão do fenômeno de solvatação em muitos sistemas, e incluem inclusive o efeito de polarização do soluto pelo solvente, efeito negligenciado em muitos modelos explícitos.

Esforços pioneiros para descrever a solvatação por modelagem computacional remontam a década de 1970, com a formulação de Campo de Reação Auto Consistente (SCRF) por Tapia e Goscinski [39] e Rivail e Rinaldi [40]. O estudo de sistemas moleculares em solução por meio de modelos contínuos de solvente teve um forte crescimento na década de 1990 e prossegue até os dias atuais.

O modelo contínuo pode ser formalmente definido como um método computacional em que o sistema líquido é separado em duas partes: a parte principal, ou parte ativa M (chamada de soluto) e uma parte secundária S (chamada solvente). O hamiltoniano eletrônico do sistema pode ser escrito como

$$
\mathcal{H}=\mathcal{H}_{M}^{(0)}+V_{\text {int }}
$$

onde $\mathcal{H}_{M}^{(0)}$ é o hamiltoniano eletrônico do soluto e $V_{\text {int }}$ representa o potencial de interação soluto-solvente. 
Nos modelos contínuos mais comuns a interação é reduzida ao potencial clássico de interação eletrostática

$$
V_{i n t} \equiv V_{\sigma}\left(\mathbf{r}, \mathbf{R}, \varrho_{M}, \epsilon\right)
$$

que depende da geometria do soluto $\mathrm{M}$, da densidade de carga $\varrho_{M}$ (modificada pelo efeito do solvente) e da constante dielétrica $\epsilon$ do solvente. A contribuição para a energia do sistema é dada por

$$
W_{M S}=\left\langle\Psi^{(f)}\left|V_{\sigma}\right| \Psi^{(f)}\right\rangle
$$

Em geral, $V_{\sigma}$ é um operador de um elétron e o cálculo de $W_{M S}$ não acarreta significativo aumento no custo computacional.

A formulação quântica destes modelos contínuos eletrostáticos requer a definição tanto do problema de calcular $\varrho_{M}$ do soluto sujeito à um potencial externo eletrostático $\Phi_{\sigma}$ quanto o problema de calcular o campo de reação do solvente $\Phi_{\sigma}$. Este problema tipicamente é não linear pois $\Phi_{\sigma}$ e $V_{\sigma}$ dependem da distribuição de carga $\varrho_{M}$. Sua solução requer, portanto, um ciclo adicional de auto consistência, resolvendo alternadamente o problema quântico para determinar $\varrho_{M}$ e o problema eletrostático clássico para determinar $\Phi_{\sigma}$.

Os modelos contínuos diferem entre si na forma de descrição de $\Phi_{\sigma}$ e de sua interação com $\varrho_{M}$. Entre as abordagens mais usadas estão o uso de expansão multipolar, de cargas imagens, diferenças finitas. Em todas as abordagens o soluto M reside em uma cavidade criada no meio dielétrico. A forma e o tamanho da cavidade são fatores cruciais na elaboração do método. Uma cavidade idealmente deveria reproduzir a forma do soluto, pois uma forma errada produz distorções na descrição do campo de reação. As cavidades usadas visam ou o uso de formas regulares como esferas, elipsóides e cilindros ou formas moleculares representadas por um conjunto de esferas sobrepostas centradas sobre os núcleos, sobre algum grupo químico do soluto M, ou que visam ainda diminuir o espaço vazio na interface entre soluto e solvente. Dentre 
este modelos, um dos mais eficientes é o modelo contínuo polarizável ou PCM (Continuum Polarizable Model) proposto por Tomasi et al em 1981 [41] e desenvolvido por seu grupo até a atualidade.

\subsubsection{O modelo contínuo polarizável}

Na versão original do PCM, a cavidade é definida em termos de esferas de raio $R_{\alpha}$, centradas sobre os núcleos atômicos, proporcionais aos raios de van der Waals

$$
R_{\alpha}=f R_{\alpha}^{v d W}
$$

onde o fator de escala padrão é de $f=1,2$ e vem de ajustes à resultados experimentais. Uma vez definida a forma e o tamanho da cavidade, o problema eletrostático com as apropriadas condições de contorno é resolvido. O potencial eletrostático clássico é obtido resolvendo a equação de Laplace e de Poisson,

$$
\begin{aligned}
\nabla^{2} \Phi(\mathbf{r})=-4 \pi \varrho_{M}(\mathbf{r}) & ; \mathbf{r} \in V_{\text {in }} \\
\nabla^{2} \Phi(\mathbf{r})=0 & ; \mathbf{r} \in V_{\text {out }}
\end{aligned}
$$

onde $V_{\text {in }}$ e $V_{\text {out }}$ são os volumes dentro e fora da cavidade.

A quantidade relevante no estudo de propriedades termodinâmicas é o trabalho necessário para induzir a densidade de carga $\varrho_{M}$ na cavidade, que é dado por

$$
\Delta G_{e l}^{(i)}=\frac{W_{M S}}{2}
$$

para um modelo rígido. Esta quantidade é equivalente a contribuição eletrostática para a energia livre de solvatação. O índice $i$ em $\Delta G_{e l}^{(i)}$ denota o nível de aproximação na descrição do efeito de polarização mútua entre soluto e solvente $(i=0$, carga rígida; $i=1$, polarização do soluto em resposta a polarização do solvente; $i=t$, sistema totalmente relaxado). 
O problema quântica corresponde a resolver a equação de Schrödinger

$$
\left[\mathcal{H}_{(0)}^{M}+V_{\sigma}\left(\mathbf{r}, \mathbf{R}, \varrho_{M}^{(t)}, \epsilon\right)\right] \Psi^{(t)}(\mathbf{r} ; \mathbf{R})=E^{(t)} \Psi^{(t)}(\mathbf{r} ; \mathbf{R})
$$

onde $(t)$ indica a solução final convergida do processo iterativo de polarização foi usado. Como o uso deste hamiltoniano, as equações de HF continuam com a mesma forma. Mas os elementos de matriz do operador de Fock diferem dos obtidos em vácuo pela adição da contribuição de $V_{\sigma}$ ao hamiltoniano de caroço h e da dependência do termo de 2 elétrons G com a densidade eletrônica $\varrho_{e l}$

$$
F_{\mu \nu}=\mathrm{h}_{\mu \nu}+\mathrm{G}_{\mu \nu}\left(\varrho_{e l}\right)+\left\langle\mu\left|V_{\sigma}\right| \nu\right\rangle
$$

Desta forma, praticamente todos os cálculos que podem ser realizados em fase gasosa (com o método de HF) podem ser realizados agora incluindo o efeito do solvente. Além disso, a livre de solvatação também pode ser calculada pela soma de diversas contribuições,

$$
\Delta G_{\text {solv }}=\Delta G_{e l}+\Delta G_{c a v}+\Delta G_{d i s}+\Delta G_{r e p}
$$

onde o termo eletrostático $\Delta G_{e l}$ já foi examinado. Os outros são os termos de cavitação $\left(\Delta G_{\text {cav }}\right)$, dispersão $\left(\Delta G_{\text {dis }}\right)$ e repulsão $\left(\Delta G_{r e p}\right)$. Informações sobre como estes termos são calculados, bem como de mais detalhes sobre os modelos contínuos de uma forma geral e de sua extensão para outros métodos além de HF, podem ser encontrados nas referências 42,45$]$.

\subsubsection{Limitações dos modelos de solvatação implícita}

A principal vantagem dos modelos contínuos é a possibilidade de introduzir a interação soluto-solvente em um tratamento puramente quântico sem a adição explícita de um único elétron, isto é, praticamente não aumenta o custo computacional. A desvantagem, é que certas propriedades moleculares que exigem uma descrição detalhada 
desta interação simplesmente não podem ser obtidas pelo modelo contínuo, ou seja, exigem a consideração de moléculas explícitas do solvente, ao menos na vizinhança do soluto. Outro problema que o modelo contínuo tem de enfrentar é o de determinar onde o tamanho da cavidade e a interface soluto-solvente, ou seja, onde termina o soluto e onde começa o solvente. Interações específicas, sobretudo na primeira camada de solvatação também representam um desafio para estes modelos, como por exemplo as ligações de hidrogênio, interação de dispersão e transferência de carga.

Modelos contínuos não são a única forma de descrever o efeito do solvente. O uso de simulação computacional é uma abordagem rigorosa, onde moléculas de solvente interagem explicitamente com o soluto tratando a interação soluto-solvente como o uso de potenciais intermoleculares analíticos (os campo de força).

\subsection{Simulação Computacional}

As diversas metodologias desenvolvidas para o estudo de simulação computacional de líquidos podem ser distinguidas entre as que são baseadas em Dinâmica Molecular (MD) ou no método Monte Carlo (MC). A principal diferença é que a dinâmica molecular se baseia na evolução temporal (determinística) das equações clássicas de movimento, enquanto que em MC, configurações de equilíbrio (que satisfazem a distribuição de probabilidades de Boltzmann) são geradas aleatoriamente, por meio de um processo estocástico.

Nos modelos moleculares de simulação computacional, a mecânica estatística de equilíbrio é usada para reproduzir tanto as relações intermoleculares quanto propriedades termodinâmicas. Os potenciais intermoleculares são fundamentais para a correta descrição destas propriedades.

No contexto da mecânica estatística clássica de equilíbrio, o estado microscópico de um sistema pode ser especificado em termos das posições e momentos. A dinâmica 
é regida pela função hamiltoniana do sistema que, em uma simulação usual de $\mathrm{N}$ partículas, é escrita em termos das posições $r_{i}$ e momentos $p_{i}$ como a soma da energia cinética (como função quadrática dos momentos) e da energia potencial (como função das posições)

$$
H=H(\mathbf{r}, \mathbf{p})=\sum_{i=1}^{N} \frac{\mathbf{p}_{i}^{2}}{2 m}+U(\mathbf{r})
$$

de seus constituintes (átomos ou moléculas).

Toda a informação sobre as interações está contida no potencial $U(\mathbf{r})$, que é específico para cada sistema, constituindo a entrada básica para a simulação computacional.

\subsubsection{O potencial de interação.}

Não existe uma forma universal para o potencial intermolecular. Os campos de força frequentemente usados em simulação computacional são potenciais efetivos, que buscam reproduzir efeitos de muitos corpos,

$$
U(\mathbf{r})=\sum_{i} \sum_{i<j} v_{i j}^{e f f}\left(\mathbf{r}_{i}, \mathbf{r}_{j}\right) .
$$

Uma forma de modelar o sistema molecular é aproximá-la por sítios localizados sobre os núcleos atômicos. A interação total é a soma das interações de pares dos distintos sítios $i$ localizados sobre a molécula $a$ (posição $\mathbf{r}_{i a}$ ) e os sítios $j$ localizados na molécula $b$ (posição $\mathbf{r}_{j b}$ ),

$$
v_{a b}\left(\mathbf{r}_{a b}, \Omega_{a}, \Omega_{b}\right)=\sum_{i \in a} \sum_{j \in b} v_{i j}\left(r_{i j}\right),
$$

onde $r_{i j}=\left|\mathbf{r}_{i a}-\mathbf{r}_{j b}\right|$.

O potencial mais usado para sistemas líquidos é o potencial de Lennard-Jones (LJ) acrescido de um termo Coulombiano (C)

$$
v_{i j}\left(r_{i j}\right)=4 \epsilon_{i j}\left[\left(\frac{\sigma_{i j}}{r_{i j}}\right)^{12}-\left(\frac{\sigma_{i j}}{r_{i j}}\right)^{6}\right]+\frac{q_{i j}}{r_{i j}} .
$$


Cada sítio do potencial é descrito por dois parâmetros $\left(\epsilon_{i}\right.$ e $\left.\sigma_{i}\right)$ e por uma carga $q_{i}$. Além disto, $\epsilon_{i j}=\left(\epsilon_{i} \epsilon_{j}\right)^{1 / 2}$ e $\sigma_{i j}=\left(\sigma_{i} \sigma_{j}\right)^{1 / 2}$. O termo atrativo em $r^{6}$ visa reproduzir as forças de van der Waals. A dependência proporcional a $r^{12}$ não tem origem física, mas vem de ajustes a dados experimentais. Já as cargas para o potencial de Coulomb dão conta das interações eletrostáticas das moléculas $a$ e $b$. Os valores para $\epsilon_{i}$ e $\sigma_{i}$ são obtidos por meio de ajustes a dados experimentais ou ainda por cálculos quânticos e em geral podem ser encontrados na literatura. Diversos grupos se dedicam exclusivamente a arte de obter estes conjuntos de parâmetros. Alguns conjuntos de notoriedade são o OPLS (Optimized Parameter for Liquid Simulation) desenvolvido no grupo de Jorgensen [46] e o AMBER (Assisted Model Building with Energy Refinement) desenvolvido por Kollman e colaboradores [47]. No caso das cargas $q_{i}$, caso não haja uma parametrização específica para o sistema estudado, é mais confiável obtê-las por meio de cálculos quânticos, usando por exemplo o ajuste CHELPG, descrito no capítulo anterior. Maiores detalhes sobre simulações computacionais podem ser encontradas nos livros de Allen e Tildesley [48], e de Frenkel e Smit [49].

\subsubsection{O método Monte Carlo.}

O estado termodinâmico de um sistema é dado por um número pequeno de parâmetros, tais como número de partículas $N$, temperatura $T$, volume $V$ e pressão $P$. Outras propriedades (potencial químico $\mu$, densidade $\rho$, etc.) podem ser derivadas de equações de estado e relações fundamentais da termodinâmica.

Dado um ponto $\Gamma$ no espaço de fase do sistema, um observável físico $\mathcal{A}$ é função deste ponto $\mathcal{A}=\mathcal{A}(\Gamma)$. O conjunto de pontos acessíveis ao sistema, ensemble, são determinados pela função densidade de probabilidade $\varrho_{\text {ens }}(\Gamma)$.

Dado um conjunto de configurações, ou estados acessíveis ao sistema, uma distribuição de probabilidades definidas a priori, as propriedades de um sistema em equi- 
líbrio termodinâmico são obtidas como médias $\langle\mathcal{A}\rangle$

$$
\langle\mathcal{A}\rangle=\frac{1}{Z} \int_{\{\Gamma\}} \mathcal{A} \varrho_{e n s} d \Gamma
$$

no espaço de fase do sistema, onde $Z$ é a função de partição,

$$
Z=\int_{\{\Gamma\}} \varrho_{e n s} d \Gamma
$$

e $\varrho_{e n s}$ é a função de densidade de probabilidade, que depende do ensemble (NVT, NpT, etc). No ensemble NVT e NpT, por exemplo, a densidade assume, respectivamente, as formas

$$
\varrho_{N V T}=\frac{1}{Z} e^{-\beta H} \quad e \quad \varrho_{N p T}=\frac{1}{Z} e^{-\beta(H+p V)},
$$

onde $\beta=\frac{1}{k_{B} T}$, com $k_{B}$ sendo a constante de Boltzmann, e a função hamiltoniana $H$ considerada aqui tem a forma (3.10).

Neste caso, a função de partição pode ser separada em uma parte relativa aos momentos, facilmente integrável e outra parte configuracional, onde reside toda a complexidade do cálculo. O cálculo das funções potenciais termodinâmicas, como entalpia e entropia, é realizado por médio de integrais multidimensionais no espaço de fase acessível ao sistema torna-se impraticável à medida que o número de constituinte do sistema aumenta. O método MC com algoritmo de Metropolis, consiste basicamente em um processo de evolução probabilística com a finalidade de obter os valores médios de propriedades em uma amostragem convenientemente escolhida, evitando assim o cálculo da função de partição do sistema.

A média é calculada sobre um número menor, das mais representativas configurações de equilíbrio, devidamente selecionadas,

$$
\langle\mathcal{A}\rangle=\frac{1}{\ell} \sum_{i=1}^{\ell} \mathcal{A}\left(\Gamma_{\ell}\right) .
$$

O método Monte Carlo responde às questões sobre como escolher estas configurações e sobre as circunstâncias em que o valor esperado de $A$ pode ser obtido desta forma. 
A ideia deste método consiste em escolher uma sequencia de configurações independentes $\left\{\Gamma_{0}, \ldots, \Gamma_{m}, \Gamma_{n} \ldots\right\}$ como o espaço de estados acessíveis ao sistema. O algoritmo de Metropolis estabelece uma regra sobre como estas configurações podem ser geradas.

A cada estado $\Gamma_{i}$ é associada uma distribuição de probabilidades $\varrho_{i}=\varrho\left(\Gamma_{i}\right)$ de tal forma que $\varrho_{m}$ depende apenas da distribuição $\varrho_{n}$ relativa ao estado imediatamente anterior. Esta dependência é realizada introduzindo uma matriz de transição $W_{m n}$,

$$
\varrho_{n}=\sum_{n} W_{m n} \varrho_{m}
$$

que satisfaz às relações

$$
W_{m n}>0 \quad \text { e } \sum_{n} W_{m n}=1 ; \forall m .
$$

A condição adicional de que a matriz $W_{m n}$ satisfaça a relação de reversibilidade microscópica

$$
\varrho_{m} W_{m n}=\varrho_{n} W_{n m}
$$

é suficiente para assegurar que, no equilíbrio, a distribuição tenha como limite a distribuição de Boltzmann. Para que isto ocorra, as probabilidades de transição devem ser escolhidas de tal forma que

$$
\frac{W_{m n}}{W_{n m}}=\frac{\varrho_{m}}{\varrho_{n}}=e^{-\beta \Delta H},
$$

onde $\Delta H=H\left(\Gamma_{m}\right)-H\left(\Gamma_{n}\right)$ é a diferença de energia entre as configurações $\Gamma_{m}$ e $\Gamma_{n}$. A relação acima não determina a matriz de transição de forma unívoca. Metropolis faz uma escolha para esta matriz, que é dada pela forma

$$
\begin{array}{rlr}
W_{m n}=e^{-\beta \Delta H / k_{B} T} \quad \Delta H \geq 0 & m \neq n \\
W_{m n}=1 & \Delta H<0 & m \neq n \\
W_{m n}=1-\sum_{m \neq n} e^{-\beta \Delta H / k_{B} T} & m=n
\end{array}
$$


Este escolha de Metropolis é que define o algoritmo que permite criar a distribuição de pontos $\left\{\Gamma_{0}, \ldots, \Gamma_{m}, \Gamma_{n} \ldots\right\}$ no espaço de fase compatíveis com a distribuição de Gibbs, ou seja, configurações de equilíbrio.

Neste trabalho, usamos o método MC conforme implementado no programa DICE [50]. Mais detalhes desta implementação podem ser encontradas nas referências [51,52]. Apresentamos apenas uma breve descrição desta implementação.

O primeiro passo consiste em gerar uma configuração inicial de um sistema de $\mathrm{N}$ moléculas confinadas em uma caixa cúbica, sujeito às condições do ensemble escolhido (em geral $N V T$ ou $N p T$ ). A partir desta, seguem-se basicamente três passos:

1) Uma nova configuração é gerada selecionando uma molécula aleatoriamente. Sobre ela são realizados um movimento aleatório de translação ao redor do centro de massa e um movimento de rotação ao redor de um eixo, também escolhido aleatoriamente, dentro de um intervalo entre $-15^{\circ}$ e $15^{\circ}$. A partir daí é usado o critério de Metropolis.

2) Calcula-se $\Delta H$. Se o valor é negativo, a configuração é aceita.

3) Caso $\Delta H>0$ é gerado um número aleatório $p \in[0,1]$. Se o número é menor que a probabilidade de transição, a configuração é aceita. Caso contrário, é rejeitada.

O processo retorna ao passo 1 com a seleção de uma nova molécula. Quando o processo é repedido para $N$ moléculas, diz-se que um ciclo é realizado. Desta forma, 1 ciclo com o método MC neste algoritmo corresponde a N passos MC.

A simulação computacional é constituída de duas partes. A primeira é o processo de termalização, que é usada para levar o sistema da configuração inicial gerada aleatoriamente até as configurações compatíveis com a distribuição de Boltzmann. Ao fim desta primeira etapa, realiza-se o processo de equilíbrio, a partir do qual as configurações geradas são guardadas. As propriedades obtidas via simulação MC aparecem como média no espaço amostral gerado. As configurações espaciais que fazem parte 
da amostragem são obtidas com o auxílio de um gerador de números aleatórios.

\subsubsection{Análise da simulação}

Propriedades termodinâmicas usuais como energia, entalpia e volume podem ser obtidas a partir da análise da simulação computacional e são expressas como médias configuracionais. Também podem ser obtidas propriedades relacionadas às flutuações estatísticas destas propriedades, como capacidade calorífica, coeficientes de expansão térmica e de compressão isobárica [53. Uma análise importante, que permite obter a estrutura do solvente, é o das chamadas funções de distribuição radial de pares, que discutiremos a seguir.

\section{Distribuição radial de pares}

A função $G(r)$ de distribuição radial de pares (RDF) permite obter características da estrutura do líquido. Por estrutura entende-se a disposição média relativa entre as moléculas. Vale ressaltar que esta informação pode ser obtida experimentalmente por técnicas de espalhamento de raios-X e difração de nêutrons.

A informação da RDF é obtida da simulação calculando o histograma de distância entre os pares $i$ e $j$,

$$
G(r)=\frac{n_{i j}(r, r+d r)}{n_{i d}(r, r+d r)}
$$

onde $n_{i j}$ é o número de pares $i j$ separados por uma distância entre $r$ e $r+d r, n_{i d}$ é o número de pares no gás ideal de mesma densidade,

$$
n_{i d}=\frac{4 \pi}{3} \rho\left[(r+d r)^{3}-r^{3}\right]
$$

A integração de $G_{i j}(r)$ em até uma distância $r$,

$$
N_{s}=\frac{4 \pi N}{V} \int_{0}^{r} G_{i j}(r) r^{2} d r
$$


dá informação sobre o número de moléculas $N_{s}$ que se distribuem radialmente ao redor de outra. O número de moléculas no primeiro pico é conhecido como número de coordenação e é usado para definir a primeira camada de solvatação. Demais camadas também podem ser associadas aos demais picos, caso existam.

Podem ser analisadas em uma simulação computacional, tanto a distribuição do solvente ao redor de um átomo específico quanto ao redor do soluto como um todo. Para este último propósito em geral a RDF dos centros de massa entre soluto e solvente são analisadas. Entretanto, no caso de moléculas alongadas este tipo de análise pode não ser adequada 54 e uma nova RDF, chamada de MDDF (Minimum Distance Distribution Function) foi proposta [55. Ela usa no histograma a menor distância entre soluto e solvente e pode ser normalizada usando uma caixa retangular em vez da distribuição esférica usual e por essa razão se ajusta melhor a moléculas planas ou alongadas. Neste trabalho, a MDDF foi usada para definir as camadas de solvatação.

\subsection{Teoria de perturbação termodinâmica e energia livre de solvatação}

Diversos algoritmos usando a combinação de mecânica estatística e amostragens de MD ou MC permitem calcular a diferença de energia livre entre dois estados. Um dos mais populares em simulação computacional é a técnica conhecida como perturbação termodinâmica de energia livre ou FEP (Free Energy Perturbation).

A diferenças de energia livre entre dois estado A e B corresponde ao trabalho necessário para mudar o sistema de A para B sobre um caminho reversível. A Hamiltoniana $H(\mathbf{p}, \mathbf{r})$ (ou somente a energia potencial $U(\mathbf{r}))$ é escrita em termos de um parâmetro $\lambda$, de tal forma que $H\left(\mathbf{p}, \mathbf{r} ; \lambda_{\mathbf{A}}\right)$ caracteriza o estado A do sistema e $H\left(\mathbf{p}, \mathbf{r} ; \lambda_{\mathbf{B}}\right)$ o estado B. Neste caso, a energia livre do sistema também será função de 
$\lambda$,

$$
G(\lambda)=-k_{B} T \ln Z(\lambda)
$$

onde $k_{B}$ denota a constante de Boltzmann, T a temperatura e Z é a função de partição isobárica

$$
Z(\lambda)=\left(h^{3 N} N !\right)^{-1} \iiint \exp \left[-(H(p, r ; \lambda)+P V) / k_{B} T\right] d V d \mathbf{p} d \mathbf{r} .
$$

A diferença de energia livre entre os estados A e B é dada por

$$
\Delta G_{B A}=G_{B}-G_{A}=-k_{B} T \ln \left[\frac{Z\left(\lambda_{B}\right)}{Z\left(\lambda_{A}\right)}\right] .
$$

O ponto chave do método consiste em expressar esta diferença como uma média sobre o ensemble [15] de referência,

$$
\Delta G_{B A}=-k_{B} T \ln \left\langle e^{-\frac{\Delta H_{B A}}{k_{B} T}}\right\rangle_{\lambda_{A}}
$$

onde $\Delta H_{B A}=H\left(p, r ; \lambda_{B}\right)-H\left(p, r ; \lambda_{A}\right)$ e $\langle\ldots\rangle_{\lambda_{A}}$ refere-se a média sobre o ensemble do sistema com o potencial gerado pelo valor específico de $\lambda_{A}$. A fórmula acima é conhecida como fórmula perturbativa [56,57], e sua aplicação é recomendada para estados A e B cuja diferença em energia sejam de no máximo $1,5 \mathrm{kcal} / \mathrm{mol}$ [58]. O caminho que leva o sistema do estado A ao estado B pode ser dividido em intervalos menores, a fim de que este critério seja satisfeito. Isto é realizado introduzindo uma nova constante de acoplamento discreta $\lambda \in[0,1]$ de tal forma que

$$
H(\lambda=0)=H_{A} \text { e } H(\lambda=1)=H_{B}
$$

e o $i$-ésimo estado intermediário é definido pela hamiltoniana $H=H\left(\lambda_{i}\right)$, dada por

$$
H\left(\lambda_{i}\right)=\lambda_{i} H_{B}+\left(1-\lambda_{i}\right) H_{A}
$$

Diferenças de energia livre podem ser calculadas, nos intervalos $\left[\lambda_{i}, \lambda_{i \pm 1}\right]$, pela relação

$$
\Delta G\left(\lambda_{i} \rightarrow \lambda_{i \pm 1}\right)=-k_{B} T \ln \left\langle e^{-\frac{\Delta H\left(\lambda_{i} \rightarrow \lambda_{i \pm 1}\right)}{k_{B} T}}\right\rangle_{\lambda_{i}}
$$


onde $\Delta H\left(\lambda_{i} \rightarrow \lambda_{i \pm 1}\right)=H\left(\lambda_{i \pm 1}\right)-H\left(\lambda_{i}\right)$. Esta relação é interessante pois mostra que é possível, com uma única amostragem (do estado definido por $\lambda_{i}$ ), calcular as duas contribuições, $\Delta G_{\lambda_{i} \rightarrow \lambda_{i+1}}$ e $\Delta G_{\lambda_{i} \rightarrow \lambda_{i-1}}$, reduzindo assim o custo computacional. Este tipo de abordagem é conhecida na literatura como amostragem de passo duplo (double-wide sampling). A forma usual, que corresponde ao cálculo em uma única direção, é chamada amostragem de passo único.

Com este procedimentos, podem ser usado quantos passos forem necessários e o cálculo da energia livre de solvatação do processo total é dado pela soma das contribuições individuais,

$$
\Delta G_{\text {total }}=G_{B}-G_{A}=\sum_{\lambda_{i}=0}^{1} \Delta G\left(\lambda_{i}\right) .
$$

Maiores informações sobre o cálculo de energia livre poder ser encontrados nas referências 5963$]$.

\subsection{A metodologia S-QM/MM}

Embora simulações clássicas sejam bastante realistas ao tratar explicitamente as moléculas de solvente e permitirem obter propriedades termodinâmicas e informações sobre a estruturais do sistema líquido, o estudo de propriedades eletrônicas e de reações químicas em geral não podem ser obtidas via mecânica clássica e a mecânica quântica obrigatoriamente tem de ser usada. Ocorre que em muitos casos, as propriedades de interesse não são afetadas pelo sistema inteiro, mas apenas uma região localizada. Uma molécula em solução, por exemplo, é afetada principalmente pelas moléculas de solvente da primeira camada de solvatação. Sendo assim, tratar com Mecânica Quântica o sistema inteiro é, na prática, desnecessário (além de impraticável).

A idéia dos métodos híbridos é juntar as duas metodologias em cálculos QM/MM onde um particionamento do sistema é criado, de tal forma que a região de maior interesse do sistema é calculada usando mecânica quântica (QM) e a vizinhança é 
tratada usando a mecânica molecular. Nesta abordagem, o hamiltoniano do sistema é escrito na forma

$$
H=H_{Q M}+H_{M M}+H_{Q M / M M} .
$$

onde $H_{Q M}$ é o hamiltoniano quântico (2.2) e $H_{M M}$ a hamiltoniana clássica (3.10). O termo $H_{Q M / M M}$ é responsável pelo acoplamento interação entre a parte quântica e a parte clássica. A grande vantagem dos métodos híbridos em relação aos modelos contínuos é a possibilidade de tratar o sistema como um todo usando moléculas explícitas. Embora seja uma maneira eficiente de se obter o efeito do solvente, este método esbarra em algumas sérias limitações. A primeira delas é sobre a maneira adequada de escolher a partição do sistema que será tratada com cálculos QM. A segunda é que em uma simulação computacional são geradas um número de enorme de configurações (tipicamente centenas de milhares) e realizar cálculos quânticos em cada uma delas, ainda que em uma parte pequena do sistema, eleva consideravelmente o custo computacional. Além disto, fazer o cálculo desta maneira não garante que o resultado convergirá e caso isto não aconteça, todo o trabalho é perdido.

A metodologia S-QM/MM (sequential Quantum Mechanics/Molecular Mechanics), proposta por Canuto e Coutinho [64], responde de maneira muito positiva às limitações dos métodos convencionais ao usar um eficiente método de amostragem para obter resultados estatisticamente convergidos com um reduzido número de cálculos quânticos. Este método propõe um desacoplamento entre a parte quântica e a parte clássica do sistema, realizando os cálculos MM e QM em duas etapas sequenciais independentes. A primeira etapa consiste de uma simulação clássica para gerar a estrutura do líquido (configurações de equilíbrio). Em geral, nesta etapa é usado o método Monte Carlo (S-MC/QM), embora não haja impedimentos para o uso da dinâmica molecular. Assim são geradas as configurações do líquido.

Duas importantes análises são realizadas nestas configurações, visando reduzir o custo computacional nos cálculos quânticos posteriores. A primeira está relacionada 
a correlação estatística entre estas configurações, que permite escolher conveniente um número reduzido de configurações para serem submetidas aos cálculos quânticos (tipicamente são menos de 100). A segunda etapa é o particionamento do sistema que será tratado explicitamente no cálculo quântico (em geral são tratados explicitamente o soluto e algumas moléculas de solvente, que podem ser as ligações de hidrogênio, a primeira camada de solvatação, etc.). A propriedades são então obtidas como médias simples dos cálculos QM realizados nestas configurações.

Esta metodologia tem uma série de vantagens em relação ao QM/MM convencional. O custo computacional é muito menor, já que o número de cálculos quânticos são reduzidos para cerca de uma centena. Além disto, eles são realizados em uma simulação já convergida. Também vale ressaltar que uma mesma simulação pode ser usada para o cálculo de várias propriedades eletrônicas. Por último, existe uma liberdade maior na escolha da partição do sistema que será submetida ao cálculo quântico.

Evidentemente, esta metodologia tem suas desvantagens. A principal está relacionada ao desacoplamento entre as partes quântica e clássica, que não permite que ela seja usada em sistemas onde este acoplamento é relevante. Ainda assim, esta abordagem tem sido usada com êxito no estudo de diversas propriedades, como estudos de espectroscopia de absorção e emissão, parâmetros de NMR, ligações de hidrogênio, solvatação diferencial, etc.

Na seção seguinte discutimos como são obtidas as propriedades de interesse, o erro estatístico associado e, principalmente, o procedimento que é usado para escolher conveniente das configurações submetidas aos cálculos QM.

\subsubsection{Médias, erros e ineficiência estatística}

Vimos que no método MC, um propriedade $\mathcal{A}$ é obtida como uma média simples

$$
\langle\mathcal{A}\rangle=\frac{1}{\ell} \sum_{i=1}^{\ell} \mathcal{A}\left(\Gamma_{\ell}\right)
$$


onde $\ell$ é o número de configurações de equilíbrio. O erro estatístico associado a esta propriedade é dado por

$$
\operatorname{err}(\langle\mathcal{A}\rangle)=\sqrt{\frac{\langle\delta \mathcal{A}\rangle^{2}}{\ell}} ; \quad\langle\delta \mathcal{A}\rangle^{2}=\left\langle\mathcal{A}^{2}\right\rangle-\langle\mathcal{A}\rangle^{2}
$$

no caso de configurações independentes e por

$$
\operatorname{err}(\langle\mathcal{A}\rangle)=\sqrt{\frac{\langle\delta \mathcal{A}\rangle^{2}}{(\ell / s)}}
$$

no caso de configurações correlacionadas, onde o $s$ é o intervalo necessário para que as configurações sejam independentes.

O intervalo de correlação $s$ é obtido a partir da função de autocorrelação $C(k)$, que pode ser calculada a partir de cada configuração acessível $\Gamma_{i}$ como sendo igual a

$$
C(k)=\frac{\left\langle\delta \mathcal{A}_{i} \delta \mathcal{A}_{i+k}\right\rangle}{\left\langle\mathcal{A}_{i}^{2}\right\rangle}
$$

onde

$$
\left\langle\delta \mathcal{A}_{i} \delta \mathcal{A}_{i+k}\right\rangle=\left\langle\mathcal{A}_{i} \mathcal{A}_{i+k}\right\rangle-\left\langle\mathcal{A}_{i}\right\rangle\left\langle\mathcal{A}_{i+k}\right\rangle
$$

Processos Markovianos permitem que os coeficientes de correlação $C(k)$ sejam bem ajustados por decaimentos exponenciais do tipo [65]

$$
C(t)=\sum_{i}^{n} c_{i} e^{-t / \tau_{i}} \quad\left(\tau_{1}>\tau_{2}>\cdots>\tau_{n}\right) .
$$

Em geral, dois tempos de correlação são suficientes para o ajuste [51]

$$
C(t)=c_{1} e^{-t / \tau_{1}}+c_{2} e^{-t / \tau_{2}},
$$

$\operatorname{com} \tau_{1}>\tau_{2}$. Deste ajuste permite obter o tempo de correlação, $\tau$, dado pela integral

$$
\tau=\int_{0}^{\infty} C(t) d t=c_{1} \tau_{1}+c_{2} \tau_{2}
$$

Como o decaimento é exponencial, em princípio seria necessário um intervalo de infinitos passos para obter configurações estatisticamente independentes $(C(k) \approx 0) \mathrm{Em}$ 
geral, para um intervalo de correlação $s=2 \tau$ a correlação já tem um valor inferior a $13 \%$, um valor baixo o suficiente para que as configurações separadas por este intervalo sejam consideradas, na prática, estatisticamente descorrelacionadas.

No S-QM/MM esta análise é realizada usando a função de autocorrelação em energia para separar as configurações descorrelacionadas. Uma vez elas são as que mais contribuem para o valor esperado de uma propriedade, somente estas são submetidas aos cálculos quânticos. Este procedimento permite obter o valor médio estatisticamente convergido com um número reduzido de cálculos quânticos e, por essa razão, reduz drasticamente o custo computacional, comparado aos métodos QM/MM convencionais.

Informações mais detalhadas da metodologia S-QM/MM, bem como de suas aplicações, podem ser encontradas no capítulo 7 da referência 64] e no capítulo 13 da referência [27] e ainda nas referências [51,52]. 


\section{Capítulo 4}

\section{Resultados}

Neste capítulo são apresentados os resultados da aplicação das técnicas discutidas no capítulo precedente no estudo da solvatação dos carbonatos de etileno e de propileno em solução aquosa. Inicialmente discutimos a geometria da molécula obtida teoricamente comparando com resultados experimentais encontrados na literatura. Seguem os estudos da moléculas em solução usando o modelo contínuo polarizável. Os resultados de simulações computacionais com o método Monte Carlo são apresentados em seguida. Nestes resultados, destacam-se um detalhado estudo das ligações de hidrogênio. O capítulo de resultados é concluído com os resultados para a energia livre de solvatação dos carbonatos usando novas simulações e a teoria de perturbação termodinâmica. Todos os cálculos quânticos deste trabalho foram realizados usando o programa Gaussian 03 [66] e todas as simulações computacionais usando o programa DICE [50].

\subsection{Moléculas isoladas}

Um dos usos mais frequentes de métodos de estrutura eletrônica consiste na determinação da geometria de equilíbrio de um sistema molecular. Por essa razão, praticamente todos os pacotes de programas contém algoritmos para obtê-la. 


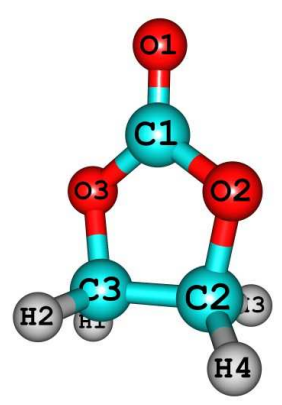

(a) EC

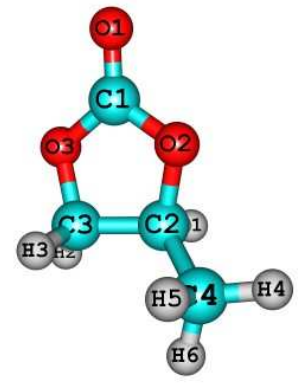

(b) $\mathrm{PC}$

Figura 4.1: Geometrias dos carbonatos de etileno (a) e de propileno (b), obtidas usando mp2/augcc-pVDZ + PCM.

Na aproximação de Born-Oppenheimer, a energia total como função das coordenadas nucleares define a superfície de energia potencial sobre a qual os núcleos se movem. Os pontos estacionários nesta superfície são de particular interesse uma vez que os pontos de mínimo correspondem a geometrias de equilíbrio, enquanto que os ponto de sela correspondem a estados de transição. Em um processo conhecido como otimização de geometria, os algoritmos em geral partem de uma geometria arbitrária e, a partir do cálculo da energia do sistema neste ponto e dos gradientes, realizam um deslocamento das coordenadas nucleares na direção de maior decréscimo da superfície, repetindo o processo até a convergência. Este algoritmo, no entanto, garante apenas que o sistema se encontra em um ponto estacionário desta superfície no final do processo. Uma forma de descobrir se o ponto estacionário é de mínimo local ou de ponto sela, consiste em calcular o espectro vibracional da molécula neste ponto no mesmo nível de cálculo em que ela foi otimizada. Os algoritmos para este cálculo são tais que, se o sistema estiver em um ponto sela, aparecem frequências negativas no espectro.

As geometrias do EC e do PC (figura 4.1) foram obtidas usando este procedimento, com a teoria de perturbação de segunda ordem (MP2) e conjunto de funções base aug-cc-pVDZ. Uma boa descrição, sobretudo do momento de dipolo, é essencial para a obtenção de resultados confiáveis no estudo de moléculas em solução e este nível de cálculo permite manter um excelente compromisso entre o custo computacio- 
nal e a acurácia nos resultados. Trabalhos na literatura mostram que ele é capaz de produzir excelentes resultados para as geometrias de equilíbrio e para o momento de dipolo [25, 26].

Existem alguns resultados na literatura, tanto teóricos quanto experimentais, sobre a geometria do EC e resultados teóricos comparando esta geometria com a do PC. Medidas para o EC na fase cristalina, realizadas na década de 50 [67], reportam uma geometria não planar com simetria $C_{2}$. Desta forma, o grupo carbonato pertence a um plano, enquanto o grupo etileno pertence a um segundo plano, que por usa vez faz um angulo de $20^{\circ}$ com o primeiro. Medidas do espectro vibracional realizadas por Angel em 1956 [68] sugeriam que a geometria do carbonato de etileno passaria da simetria $C_{2}$ no estado sólido para uma geometria planar com simetria $C_{2 v}$ nas fases líquida e gasosa. Novas medidas foram realizadas posteriormente [69 71, no entanto, e colocaram em dúvida este resultado. Medidas posteriores do espectro de microondas 72 mostraram que a molécula de EC possui uma geometria não planar, com o anel levemente torcido, formando um ângulo ângulo diedral (ver figura 4.1) $O 2-C 2-C 3-O 3$ de $24,8^{\circ}$. Estes trabalhos concluem também que a geometria plana do anel é um estado de transição para a conformação com anel invertido e que a geometria não planar é mais estável em apenas $0,67 \mathrm{kcal} / \mathrm{mol}$ em relação a geometria plana. Estes resultados foram confirmados posteriormente com resultados de difração de nêutrons [73], para o EC na fase gasosa e mais recentemente usando dinâmica molecular [8]. Já no caso do PC existem apenas trabalhos teóricos sobre sua geometria como o de dinâmica molecular citado acima e um trabalho teórico mais recente [74] sobre o espectro vibracional que também confirmam uma geometria não planar.

Os resultados obtidos em nossos cálculos são compatíveis com estes últimos trabalhos (tabela 4.1). O ângulo diedral $O 2-C 2-C 3-O 3$ obtido foi de $27,1^{\circ}$ para o EC e de $26,7^{\circ}$ para o PC. O cálculo do espectro infravermelho destas geometrias 
Tabela 4.1: Parâmetros estruturais obtidos teoricamente para o EC e PC isolados e tratando o solvente com o PCM comparados com resultados experimentais tirados da literatura

\begin{tabular}{|c|c|c|c|c|c|c|}
\hline & & \multicolumn{3}{|r|}{$\mathrm{EC}$} & \multicolumn{2}{|c|}{$\mathrm{PC}$} \\
\hline & & gás & $\mathrm{PCM}$ & experimental [73] & gás & PCM \\
\hline Distâncias & $\mathrm{C} 1-\mathrm{O} 1$ & 1,200 & 1,215 & 1,203 & 1,204 & 1,216 \\
\hline \multirow[t]{5}{*}{$(\AA)$} & $\mathrm{C} 1-\mathrm{O} 2$ & 1,370 & 1,357 & 1,342 & 1,371 & 1,354 \\
\hline & $\mathrm{C} 1-\mathrm{O} 3$ & 1,373 & 1,357 & 1,342 & 1,374 & 1,358 \\
\hline & $\mathrm{O} 2-\mathrm{C} 2$ & 1,446 & 1,461 & 1,457 & 1,453 & 1,470 \\
\hline & $\mathrm{O} 3-\mathrm{C} 3$ & 1,446 & 1,461 & 1,457 & 1,445 & 1,459 \\
\hline & $\mathrm{C} 2-\mathrm{C} 3$ & 1,528 & 1,526 & 1,522 & 1,529 & 1,528 \\
\hline Ângulos & $\mathrm{O} 1-\mathrm{C} 1-\mathrm{O} 2$ & 124,8 & 124,2 & 124,2 & 125,0 & 124,4 \\
\hline \multirow[t]{4}{*}{$\left(^{\circ}\right)$} & $\mathrm{O} 2-\mathrm{C} 1-\mathrm{O} 3$ & 110,4 & 111,5 & 111,7 & 110,3 & 111,6 \\
\hline & $\mathrm{C} 1-\mathrm{O} 2-\mathrm{C} 2$ & 108,4 & 108,4 & 108,7 & 108,9 & 108,7 \\
\hline & $\mathrm{C} 1-\mathrm{O} 3-\mathrm{C} 3$ & 108,4 & 108,4 & 108,7 & 108,2 & 108,1 \\
\hline & $\mathrm{O} 2-\mathrm{C} 2-\mathrm{C} 3$ & 102,5 & 102,3 & 102,2 & 101,8 & 101,5 \\
\hline Diedros & $\mathrm{O} 2-\mathrm{C} 2-\mathrm{C} 3-\mathrm{O} 3$ & 27,1 & 26,0 & 24,8 & 26,7 & 25,8 \\
\hline \multirow[t]{3}{*}{$\left({ }^{\circ}\right)$} & $\mathrm{C} 1-\mathrm{O} 2-\mathrm{C} 2-\mathrm{C} 3$ & $-22,9$ & $-22,1$ & $-21,3$ & $-22,5$ & -22 \\
\hline & $\mathrm{C} 1-\mathrm{O} 3-\mathrm{C} 3-\mathrm{C} 2$ & $-22,9$ & $-22,1$ & $-21,3$ & $-22,5$ & $-22,04$ \\
\hline & $\mathrm{O} 2-\mathrm{C} 1-\mathrm{O} 3-\mathrm{C} 3$ & 9,4 & 9,1 & 9,0 & 9,2 & 8,8 \\
\hline
\end{tabular}

resultaram em frequências positivas. Para efeito de comparação, também obtivemos o EC na simetria $C_{2 v}$ com anel planar. Neste caso, de fato, aparece uma frequência negativa no espectro infravermelho, o que confirma se tratar de um estado de transição. A diferença de energia entre as duas conformações obtidas teoricamente foi de 0,42 kcal/mol. A geometria do PC se mostrou bastante próxima a do EC, não sendo afetada significativamente pela existência do grupo metil.

Outra propriedade de interesse que possui resultados experimentais reportados na 
literatura é o momento de dipolo. Em geral, o valor mais citado é o obtido por Kempa e Lee [75] em 1958, de 4, 87 D para o EC e de 4, 94 D para o PC. Resultados posteriores, no entanto, exibem algumas discrepâncias em relação a estes valores. Medidas de microondas [72] sugerem um momento de dipolo de 5,33 \pm 0,15 D para o EC. Em uma medida mais recente [5], foi reportado o valor de 4,81 D para o EC e de 5,36 D para o PC.

Os resultados obtidos em nossos cálculos foram de 5, 39 D para o EC e de 5,61 D. Desta forma, o nosso resultado para o momento de dipolo do EC é muito próximo do valor obtido com microondas. Mas devido à discrepância entre os resultados experimentais, Chernyak ressalta em seu trabalho [5] que novas medidas experimentais são necessárias para que se saiba qual dos valores é mais confiável.

Como estamos interessados no estudo dos carbonatos em água, estes resultado não são ruins, uma vez que quando em solução, ocorre o processo de polarização do soluto pelo solvente que tende naturalmente a aumentar o momento de dipolo. Sobre a geometria, vale ressaltar que os pequenos desvios da planaridade devem influenciar pouco o processo de solvatação, já que a parte hidrofílica não é afetada por eles. Além disto, Silva e Freitas [9] usam a geometria plana em seu estudo e obtém excelentes resultados para as propriedades termodinâmicas dos líquidos puros. Baseados nestes resultados, decidimos manter este nível de cálculo (MP2/aug-ccpVDZ) em todos os cálculos quânticos posteriores neste trabalho, exceto no cálculo de $\Delta G_{\text {solv }}$ com o PCM, cuja razão discutiremos em seguida.

O estudo da molécula em solução, a ser discutido na próxima seção, foi iniciado usando solvatação implícita com o PCM, seguido de simulações clássicas mais realistas com o método Monte Carlo e moléculas explícitas de solvente. 


\subsection{Solvatação implícita}

As geometrias em solução foram obtidas usando o modelo contínuo polarizável PCM. Como pode ser observado nos dados estruturais da tabela 4.1, não ocorrem mudanças significativas na geometria das moléculas devido ao efeito do solvente. Ocorre, porém, uma significativa polarização do soluto e o momento de dipolo calculado foi de 7, 35 D e 7,65 D para o EC e PC, respectivamente. Desta forma, tanto o EC quanto o PC sofrem o mesmo aumento no dipolo, de $36 \%$ em relação à fase gasosa. Isto mostra que o grupo metil do PC não afeta significativamente a polarização da molécula de PC. Usando a metodologia CHELPG, foram ajustadas as cargas parciais em cada átomo, a fim de serem usadas posteriormente no campo de força da simulação clássica.

Tabela 4.2: Ajuste de cargas usando CHELPG para os carbonatos isolados (gás) e em água(PCM)

\begin{tabular}{ccccccc}
\hline \multirow{2}{*}{ Espécie } & \multicolumn{2}{c}{$\mathrm{EC}$} & & \multicolumn{2}{c}{$\mathrm{PC}$} \\
\cline { 2 - 3 } \cline { 6 - 6 } Atômica & gás & PCM & & gás & PCM \\
\hline O1 & $-0,528$ & $-0,653$ & & $-0,526$ & $-0,650$ \\
C1 & 0,842 & 0,945 & & 0,868 & 0,957 \\
O2 & $-0,393$ & $-0,441$ & & $-0,455$ & $-0,498$ \\
O3 & $-0,393$ & $-0,441$ & & $-0,445$ & $-0,483$ \\
C2 & 0,128 & 0,135 & & 0,306 & 0,333 \\
C3 & 0,128 & 0,135 & & 0,208 & 0,192 \\
H1 & 0,056 & 0,085 & & 0,018 & 0,053 \\
H2 & 0,052 & 0,075 & & 0,028 & 0,061 \\
H3 & 0,056 & 0,085 & & 0,032 & 0,060 \\
H4 & 0,052 & 0,075 & & 0,135 & 0,135 \\
C4 & & & & $-0,328$ & $-0,348$ \\
H5 & & & 0,100 & 0,109 \\
H6 & & & 0,059 & 0,079 \\
\hline
\end{tabular}


Como mostram os dados da tabela 4.2, a principal diferença entre as cargas obtidas com PCM e as cargas de fase gasosa é um pequeno aumento na carga do grupo carbonato.

Usando o modelo contínuo calculamos ainda a energia livre de solvatação das moléculas. Em geral, os modelos contínuos reproduzem com precisão o termo eletrostático da energia livre de solvatação, mas erram no cálculo dos termos não eletrostáticos, principalmente no termo de cavitação. Uma vez que a cavidade no PCM é construída a partir de esferas de van der Waals sobre os núcleos, nem sempre esta construção é realista o suficiente para produzir bons resultados. Com base nisto, foi desenvolvida uma nova forma de construir a cavidade, conhecida pelo acrônimo UAHF [76], com um conjunto de parâmetros específicos para o cálculo da energia livre de solvatação, que deve ainda ser realizado no nível de cálculo HF com funções base 6-31G(d). Este nível de cálculo é recomendado na literatura [77] como o mais confiável e o uso de qualquer outro nível, ainda que em princípio mais elaborado, pode produzir resultados inferiores [78].

A tabela 4.3 mostra a energia livre de solvatação calculada usando este procedimento e calculada usando o PCM padrão. A contribuição eletrostática é dominante, como era esperado devido ao momento dipolo alto das duas moléculas. A principal diferença entre os dois métodos está no termo não eletrostático.

Tabela 4.3: Energia livre de solvatação, $\Delta G_{\text {solv }}$ (em $\mathrm{kcal} / \mathrm{mol}$ ), calculada usando o PCM padrão e com modelo UAHF para a cavidade, no nível de cálculo HF / 6-31G(d).

\begin{tabular}{cccccc}
\hline & \multicolumn{2}{c}{$\mathrm{EC}$} & & \multicolumn{2}{c}{ PC } \\
\cline { 2 - 3 } \cline { 5 - 6 } \cline { 5 - 6 } & PCM-UAHF & PCM & & PCM-UAHF & PCM \\
\hline$\Delta G_{e l}$ & $-13,31$ & $-12,22$ & & $-12,95$ & $-12,17$ \\
$\Delta G_{n e l}$ & 0,40 & 4,64 & & 0,96 & 6,25 \\
\hline$\Delta G_{\text {solv }}(\mathrm{kcal} / \mathrm{mol})$ & $-12,91$ & $-7,58$ & & $-11,99$ & $-5,92$ \\
\hline
\end{tabular}


O PCM-UAHF prevê um resultado bem menor que o PCM padrão. A consistência destes resultados será discutida posteriormente, comparando os resultados com os valores obtidos usando simulação computacional e teoria de perturbação termodinâmica.

Em síntese, o modelo contínuo mostra que o dipolo das moléculas aumenta consideravelmente e que ambos os carbonatos são bastante estáveis em solução aquosa. Novamente observou-se uma influência muito pequena do grupo metil sobre as propriedades calculadas. Uma contribuição importante, que no entanto não pode ser estudada usando modelos contínuos, é a das ligações de hidrogênio. Na próxima seção, apresentamos o resultado da simulação usando solvente explícito e o estudo destas ligações.

\subsection{Simulação computacional}

Foram realizadas simulações computacionais de um carbonato (EC ou PC) com 700 moléculas de água representando o solvente, no ensemble NVT, à uma temperatura de $300 \mathrm{~K}$ e densidade igual a $1 \mathrm{~g} / \mathrm{cm}^{3}$. O potencial intermolecular usado foi o de Lennard-Jones + Coulomb $(\mathrm{LJ}+\mathrm{C})$. Para os carbonatos, os parâmetros usados para o potencial de LJ foram os mesmos usados por Silva e Freitas [9] em seu estudo sobre os carbonatos como líquidos puros (tabela 4.4). Embora estejamos tratando os carbonatos em água, estes parâmetros em geral não sofrem mudanças significativas de um solvente para o outro. Já as cargas parciais do potencial de Coulomb são bastante influenciadas pelo meio no qual o soluto está inserido. Por essa razão, foram usadas as cargas obtidas nos cálculos quântico (incluindo a polarização usando o PCM) apresentadas na tabela 4.2. No caso das moléculas de água, uma grande quantidade de modelos para simular suas propriedades foram desenvolvidos ao longo do tempo [79]. O modelo usado neste trabalho é o Simple Point Charge (SPC), proposto em 1981 por 
Tabela 4.4: Parâmetros do potencial de Lennard-Jones ( $\varepsilon$ e $\sigma$ ) e Coulomb (q) usados na simulação, para as moléculas de EC e PC.

\begin{tabular}{ccc}
\hline & $\varepsilon(k c a l / m o l)$ & $\sigma(\AA)$ \\
\hline O1 & 0,210 & 2,96 \\
C1 & 0,105 & 3,75 \\
O2 e O3 & 0,170 & 3,00 \\
C2-C4 & 0,066 & 3,50 \\
H1-H6 & 0,015 & 2,42 \\
\hline
\end{tabular}

Berendsen et al [80] para estudar água líquida em condições normais de temperatura e pressão. Uma simulação inicial de 100000 ciclos foi realizada para cada um dos carbonatos, para que o sistema entrasse em equilíbrio termodinâmico. Com sistema em equilíbrio termodinâmico, foram realizadas simulações de 200000 ciclos. Desta forma foram geradas da ordem de $10^{7}$ configurações de equilíbrio em cada simulação.

A figura 4.2 mostra a função de autocorrelação em energia obtida da simulação computacional, bem como o ajuste de uma dupla função exponencial. De acordo com o ajuste, um intervalo de 2000 ciclos de passos MC corresponde a uma correlação inferior a $13 \%$ em ambas as simulações.

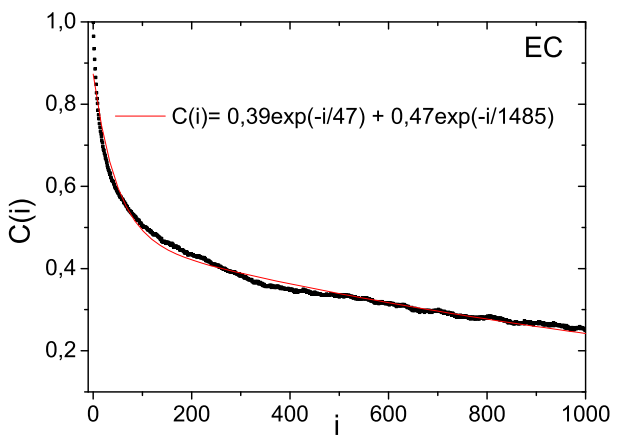

(a)

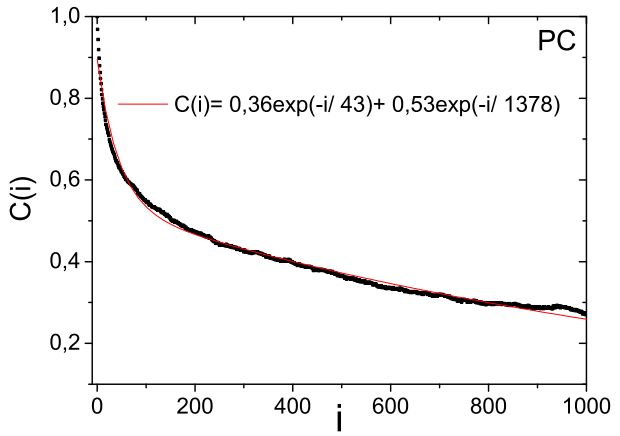

(b)

Figura 4.2: Função de autocorrelação em energia e ajuste da dupla função exponencial. 
Este intervalo de 2000 ciclos foi usado para selecionar 100 configurações descorrelacionadas em cada simulação, usadas posteriormente nos cálculos quânticos. A energia de interação entre soluto solvente foi de $-39,1 \pm 4,1 \mathrm{kcal} / \mathrm{mol}$ para o EC e de $-41,5 \pm 4,4 \mathrm{kcal} / \mathrm{mol}$ para o $\mathrm{PC}$.

\subsubsection{Ligações de hidrogênio}

Em sistemas polares, as ligações de hidrogênio (LH) constituem o principal tipo de interação entre soluto e solvente. O estudo detalhado destas ligações torna-se, portanto, crucial no entendimento do processo de solvatação. Uma maneira sistemática de identificá-las, baseada em um critério energético e geométrico [81,82], tem sido usada com êxito [83, 84] na descrição de ligações de hidrogênio em líquidos. Nesta abordagem, três critérios são estabelecidos: um critério energético $E_{l i g}$ para a energia de interação entre soluto solvente, um critério de distância $R_{O-O}$ entre os oxigênios do soluto e da água, e um critério angular $\Theta_{O O H}$ entre o oxigênio do soluto e a hidroxila da água. Uma molécula de água faz LH quando ela satisfaz estes três critérios, ou seja, são as mais próximas do soluto, interagem mais fortemente e tem uma orientação voltada para o soluto.

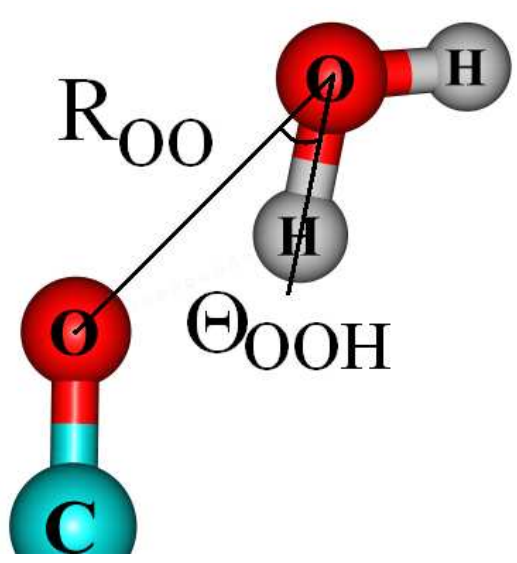

Figura 4.3: Ilustração dos critérios de distância $\left(R_{O-O}\right)$ e ângulo $\left(\Theta_{O O H}\right)$ para o o caso de um oxigênio no papel de aceitador na ligação de hidrogênio. 


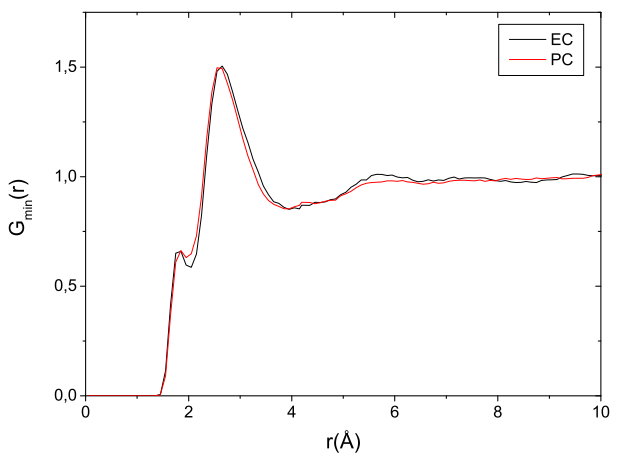

(a)

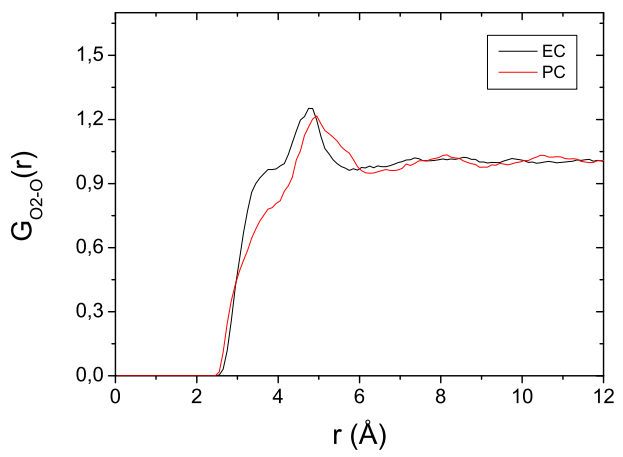

(c)

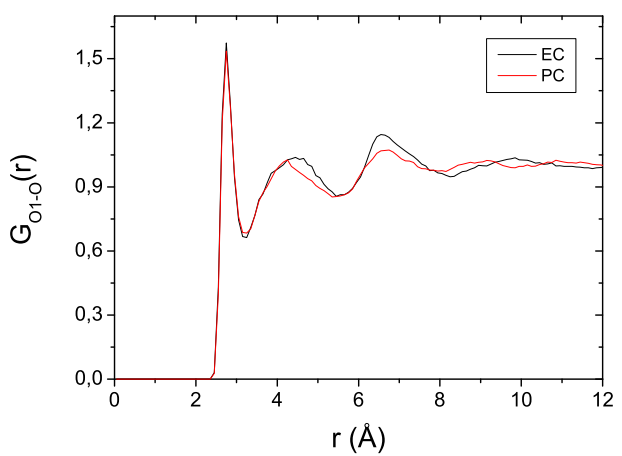

(b)

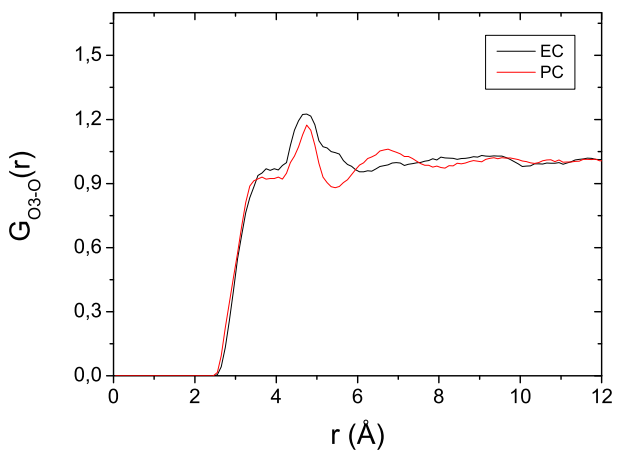

(d)

Figura 4.4: Funções de distribuição de mínima distância (4.4a) e radial de pares entre os oxigênios dos carbonatos e o oxigênio da água 4.4b, 4.4c e 4.4d).

A análise da $\operatorname{RDF} G_{\min }(r)$ de mínima distância (figura 4.4a) mostra que 25 moléculas de água formam a primeira camada de solvatação para ambos os carbonatos, se estendo até uma distância de 4 A. O critério de distância pode ser estabelecido a partir do gráfico da $\operatorname{RDF} G_{O-O}(r)$ entre um dos oxigênios do soluto e o oxigênio da água (figura 4.4). Nesta figura podemos observar que o perfil do gráfico é o mesmo para ambos os carbonatos, ou seja, não existem mudanças significativas na estrutura entre o soluto e o solvente ao redor do grupo carbonato. Uma diferença importante entre estas figuras, é que é possível distinguir claramente camadas ao redor do oxigênio O1 (figura 4.4b) e um primeiro pico bastante pronunciado. 


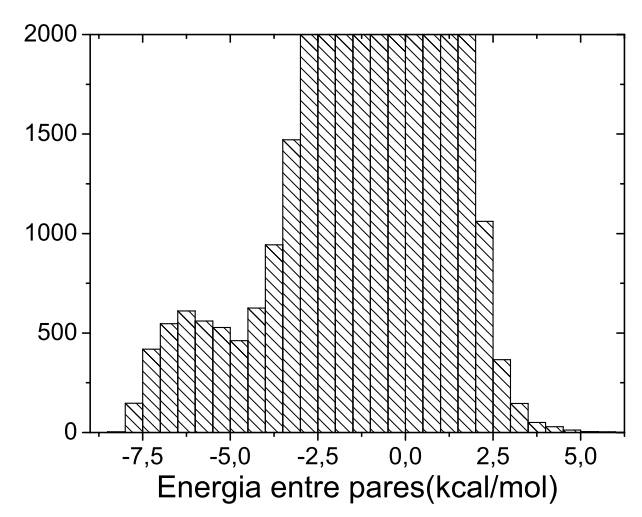

Figura 4.5: Energia de ligação entre os pares soluto-solvente.

Este primeiro pico está associado às moléculas do soluto que fazem ligações de

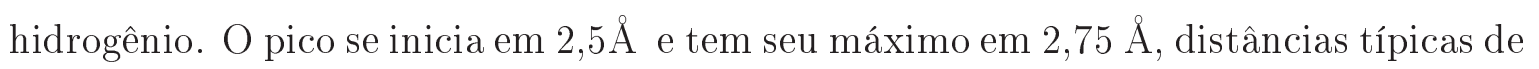
ligações de hidrogênio. A extensão deste pico é estabelecido como critério de distância, $R_{O-O} \leq 3,2 \AA$. É interessante notar que a integração deste pico nos dá um número de moléculas de águas igual a 2,6 em ambas as simulações, mas não se pode garantir que todas elas fazem LH, e os critérios adicionais devem ser analisados. A figura 4.4 mostra ainda que não aparecem pico semelhante no perfil da $G_{O-O}(r)$ dos outros oxigênios O2 e $\mathrm{O} 3$ (figuras $4.4 \mathrm{c}$ e 4.4d), o que sugere que LH sejam realizadas apenas no oxigênio O1.

O critério energético é obtido a partir da análise da energia de ligação entre as moléculas de água e o soluto. Esta análise aparece na figura 4.5 sob a forma de um histograma. As ligações de hidrogênio pertencem ao primeiro grupo de moléculas, cuja energia está no intervalo que se estende de $-8 \mathrm{kcal} / \mathrm{mol}$ até $-5 \mathrm{kcal} / \mathrm{mol}$. A partir do histograma tomamos como critério de energia o valor de $E_{\text {lig }} \leq-5 \mathrm{kcal} / \mathrm{mol}$.

Uma maneira semelhante pode ser usada para extrair o critério angular, a partir de um histograma dos ângulos entre o oxigênio do soluto e a hidroxila da água. Em geral este critério não é tão preciso quanto os anteriores e nem sempre um per- 


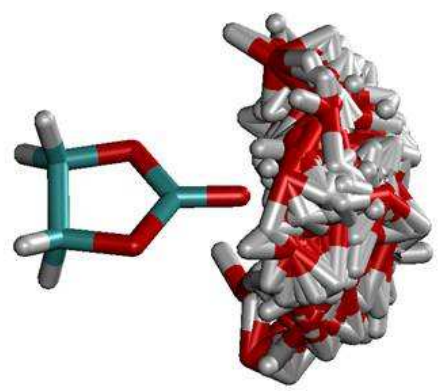

(a)

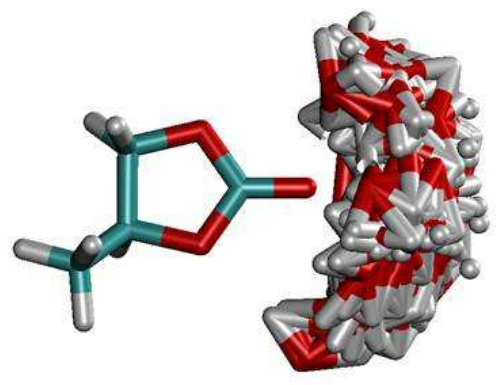

(b)

Figura 4.6: Superposição de 100 configurações do soluto acrescido das ligações de hidrogênio.

fil característico pode ser observado. Este foi o nosso caso. Tomamos então como critério angular um ângulo típico de ligação de hidrogênio, $\Theta_{O O H} \leq 40^{\circ}$. A análise das LH foi realizada em 100 configurações descorrelacionadas, com base nos critérios $R_{O-O} \leq 3,2 \AA, E_{l i g} \leq-5 \mathrm{kcal} / \mathrm{mol}$ e $\left.\Theta_{O O H} \leq 40^{\circ}\right)$.

Tabela 4.5: Número de ligações de hidrogênio (LH) encontradas nas configurações obtidas na simulação.

\begin{tabular}{|c|c|c|}
\hline & $\mathrm{EC}$ & $\mathrm{PC}$ \\
\hline$\left\langle R_{O-O}\right\rangle$ & $2,78 \pm 0,14$ & $2,80 \pm 0,15$ \\
\hline$\left\langle E_{l i g}\right\rangle$ & $-6,3 \pm 0,7$ & $-6,3 \pm 0,7$ \\
\hline$\left\langle\theta_{O O H}\right\rangle$ & $13 \pm 7$ & $13 \pm 7$ \\
\hline Números de LH & \multicolumn{2}{|c|}{ Configurações } \\
\hline 0 & 10 & 8 \\
\hline 1 & 46 & 46 \\
\hline 2 & 42 & 40 \\
\hline 3 & 2 & 6 \\
\hline$\langle N\rangle$ & 1,4 & 1,4 \\
\hline
\end{tabular}


Esta análise mostrou (tabela 4.5) que o mesmo número de LH são formadas em média nas simulações de EC e PC em água, em média 1,4. Além disto, como pode ser observado na figura 4.6 são formadas LH apenas no oxigênio O1 de cada carbonato, consistente com o perfil observado nas RDFs.

A influência das ligações de hidrogênio sobre o momento de dipolo das moléculas solvatadas foi investigada realizando cálculos quânticos desta propriedade nas 100 configurações descorrelacionadas. As moléculas que realizavam LH foram consideradas explicitamente no cálculo, e 350 moléculas adicionais foram tratadas no cálculos como cargas pontuais (c.p.), gerando um campo eletrostático que herda as propriedades do solvente (figura 4.7).

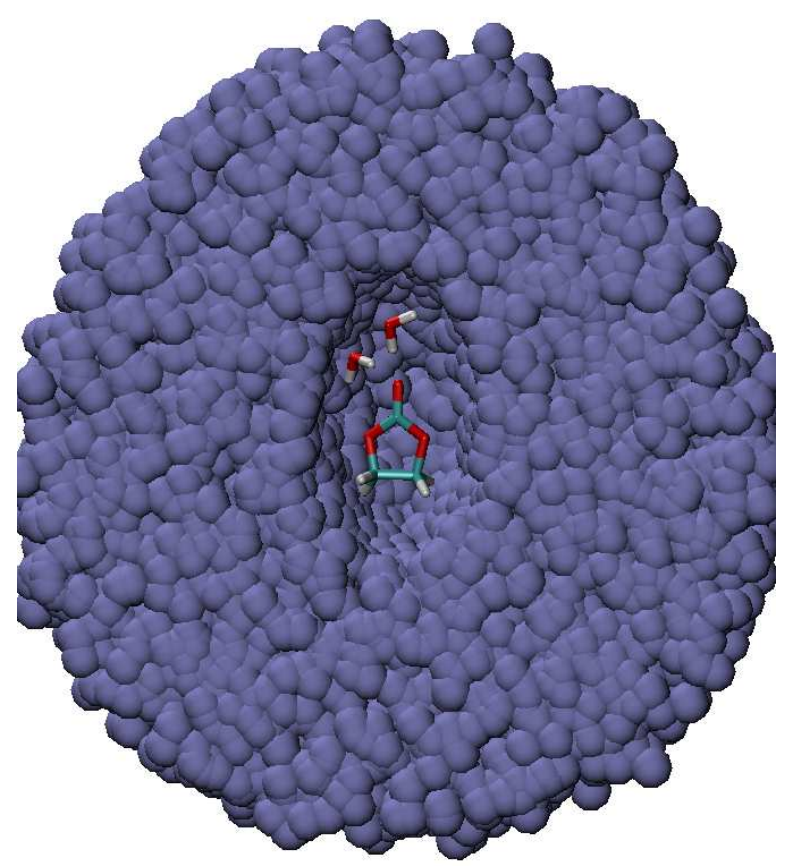

Figura 4.7: Representação esquemática de uma das configurações, neste caso de uma molécula de EC e 2 LH explícitas envoltas por 350 moléculas de água tratadas como cargas pontuais, usadas no cálculo quântico do momento de dipolo. 
Tabela 4.6: Momento de dipolo de complexos carbonato-LH, isolados e em meio, neste caso representado por 350 moléculas de água tratadas como cartas pontuais (c.p.).

\begin{tabular}{ccc}
\hline & $\mathrm{M}=\mathrm{EC}$ & $\mathrm{M}=\mathrm{PC}$ \\
\hline $\mathrm{M}+0 \mathrm{LH}$ & 5,71 & 5,95 \\
$\mathrm{M}+1 \mathrm{LH}$ & $7,47 \pm 0,12$ & $8,07 \pm 0,08$ \\
$\mathrm{M}+2 \mathrm{LH}$ & $8,94 \pm 0,24$ & $9,14 \pm 0,28$ \\
$\mathrm{M}+3 \mathrm{LH}$ & $10,2 \pm 1,4$ & $10,5 \pm 0,5$ \\
\hline Média & $7,97 \pm 0,13$ & $8,48 \pm 0,14$ \\
\hline $\mathrm{M}+0 \mathrm{LH}+350 \mathrm{H}_{2} \mathrm{O}$ (c.p.) & $7,80 \pm 0,09$ & $8,25 \pm 0,16$ \\
$\mathrm{M}+1 \mathrm{LH}+350 \mathrm{H}_{2} \mathrm{O}$ (c.p.) & $9,33 \pm 0,16$ & $10,14 \pm 0,13$ \\
$\mathrm{M}+2 \mathrm{LH}+350 \mathrm{H}_{2} \mathrm{O}$ (c.p.) & $10,9 \pm 0,2$ & $11,2 \pm 0,3$ \\
$\mathrm{M}+3 \mathrm{LH}+350 \mathrm{H}_{2} \mathrm{O}$ (c.p.) & $12,4 \pm 2,2$ & $13,1 \pm 0,7$ \\
\hline & $9,9 \pm 0,2$ & $10,6 \pm 0,2$ \\
\hline
\end{tabular}

Os resultados dos cálculos, apresentados na tabela 4.6, mostram que o momento de dipolo dos complexos carbonato-água são maiores que o das moléculas isoladas, em 2,6 D no caso de EC e em 2,9 D no caso do PC, ou seja, essencialmente a soma dos dipolos das moléculas isoladas (o valor atribuído ao dipolo da molécula de água na fase líquia é de cerca de 2,6 D [26]).

Canuto e Coutinho, estudando fenol e seu radical, concluíram que a análise do soluto + ligações de hidrogênio pode ser essencial para a compreensão da estabilidade das moléculas solvatadas [16]. Sob este ponto de vista, nossos resultados mostram que além do processo de polarização, as ligações de hidrogênio também contribuem para a estabilidade das moléculas em solução. O dipolo dos complexos sofrem ainda um aumento de cerca de $25 \%$ quando o efeito do solvente é colocado por meio das 350 moléculas de água tratadas como cargas pontuais.

Os resultados apresentados nesta seção mostram que as ligações de hidrogênio são rigorosamente as mesmas, com igual número, energia média de ligação, distância, etc. Nas duas moléculas as LH são formadas apenas no oxigênio O1 dos carbonatos. 
Isto pode ser relacionado a cadeia hidrofóbica das moléculas. Como o oxigênio O1 se encontra bastante distante da cadeia hidrofóbica, o grupo metil no PC não é capaz de afetar as LH que são realizadas neste átomo. Podemos concluir, por esta mesma razão que cadeias maiores tampouco afetariam de maneira significativa. Um ponto importante onde estas cadeias pode afetar é na estabilidade das moléculas. Na próxima seção, apresentamos o resultado do cálculo da energia livre de solvatação usando o modelo explícito.

\subsection{Energia livre de solvatação.}

A energia livre de solvatação $\Delta G_{\text {solv }}$ foi calculada usando simulações computacionais e a teoria de perturbação termodinâmica. O cálculo foi realizado usando o procedimento hipotético de aniquilação do soluto aplicado ao ciclo termodinâmico da figura 4.8. Dado um soluto $M$ rígido (sem graus de liberdade internos), a energia livre

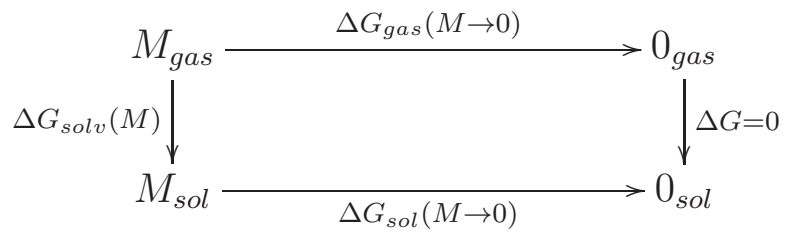

Figura 4.8: Ciclo termodinâmico usado no cálculo da energia livre de solvatação

de aniquilação da molécula isolada $\Delta G_{\text {gas }}(M \rightarrow 0)$ é nula e a energia livre de solvatação, é igual em módulo mas com sinal oposto a energia livre de aniquilação da molécula em meio $\Delta G_{\text {solv }}(M)=-\Delta G_{\text {sol }}(M \rightarrow 0)$. Ocorre que o cálculo de $\Delta G_{\text {sol }}(M \rightarrow 0)$ é mais simples que o cálculo de $\Delta G_{\text {solv }}(M)$, podendo ser calculada usando um parâmetro $\lambda$ que diminua o conjunto de parâmetros $\{q, \varepsilon, \sigma\}$ do potencial gradativamente a zero.

Em nosso caso, este procedimento foi separado em três etapas. Na primeira etapa os parâmetros de carga $q$ do potencial de Coulomb foram gradativamente reduzidos 
usando 9 fatores: $\lambda=1,00 ; 0,95 ; 0,90,0,80 ; 0,70 ; 0,60 ; 0,40 ; 0,20$ e 0,00 . Na segunda etapa foram reduzidos os parâmetros $\varepsilon$ até $1 \%$ usando 5 fatores: $\lambda=1,00 ; 0,75$; 0,$50 ; 0,25$ e 0,01. Finalmente, com as cargas zeradas e com os $\varepsilon$ reduzidos a $1 \%$, os parâmetros $\sigma$ foram reduzidos a zero por 6 fatores: 1,$0 ; 0,80 ; 0,60 ; 0,40 ; 0,20$ e 0,00 . Nas duas primeiras etapas a técnica de dupla amostragem (double-wide sampling), onde uma simulação realizada com o parâmetro multiplicado pelo fator $\lambda_{i}$ é usada para calcular a variação de energia para os estados perturbados com $\lambda_{i-1}$ e $\lambda_{i+1}$, pode ser usada para reduzir o número de simulações para 4 na primeira etapa ( $\operatorname{com} \lambda=$ 0,$95 ; 0,80 ; 0,60$ e 0,20 e perturbados para 1,00 e 0,$90 ; 0,90$ e 0,$70 ; 0,70$ e 0,40 e por fim 0,40 e 0,00$)$ e 2 na segunda $(\lambda=0,75$ e 0,25 e, perturbados para 1,00 e 0,50 ; e $0,5$ e 0,01$)$. Na terceira etapa, devido às características do potencial repulsivo, não é recomendado o uso da dupla amostragem e realizamos as 5 simulações, com os fatores mostrados acima. Ao todo são, portanto, necessárias 11 simulações computacionais.

Cada simulação foi realizada no ensemble NpT, usando 1 molécula de soluto e 500 moléculas de solvente, à uma temperatura de 298K e pressão de 1 atm. Foram usados 75000 ciclos MC para termalização e 450000 ciclos $\left(2,25 \times 10^{8}\right.$ passos) MC no equilíbrio. Para uma estimativa do erro associado ao cálculo, este processo foi repetido 3 vezes. Desta forma, para cada molécula foram realizadas ao todo 33 simulações. Vemos assim, que o cálculo de $\Delta G_{\text {solv }}$ usando este procedimento demanda a um razoável esforço computacional.

Novamente os resultados foram separados em contribuições eletrostáticas $\left(\Delta G_{e l}\right)$ e não eletrostáticas $\left(\Delta G_{n e l}\right)$, e são apresentados na tabela 4.7 .

Os resultados obtidos, de $-15,1 \pm 0,8 \mathrm{kcal} / \mathrm{mol}$ para o EC e de $-15,3 \pm 1,2$ $\mathrm{kcal} / \mathrm{mol}$ para o PC, mostram que ambos os carbonatos são igualmente estáveis em água. O fato da contribuição eletrostática ser muito próximas para as duas moléculas é consistente com a estatística de ligações de hidrogênio das moléculas, bem como com momento de dipolo em solução, que também são muito próximos. Também vimos na 
Tabela 4.7: Energia livre de solvatação $\Delta G_{\text {solv }}$, em kcal $/ \mathrm{mol}$.

\begin{tabular}{ccccccccccc}
\hline & \multicolumn{3}{c}{$\mathrm{EC}$} & & & \multicolumn{3}{c}{$\mathrm{PC}$} \\
\cline { 2 - 4 } \cline { 5 - 8 } & & $-14,1$ & \pm & 0,2 & & $-14,4$ & \pm & 0,1 \\
$\Delta G_{e l}$ & $-1,0$ & \pm & 0,6 & & $-0,9$ & \pm & 1,2 \\
\hline$\Delta G_{n e l}$ & $-15,1$ & \pm & 0,8 & & $-15,3$ & \pm & 1,2 \\
\hline
\end{tabular}

simulação que ambas as moléculas tem 25 moléculas na primeira camada de solvatação, então é razoável que os termos não eletrostáticos sejam parecidos.

O resultado usando o PCM-UAHF concorda melhor com os valores usando FEP, diferindo no termo eletrostático em apenas $1 \mathrm{kcal} / \mathrm{mol}$. Este modelo também tem melhores resultados para o termos não eletrostático que o PCM padrão. Ainda assim, o modelo contínuo fornece uma contribuição positiva para o termo não eletrostático, enquanto que na FEP este resultado é negativo. Esta discrepância pode estar relacionada a dificuldade já mencionada que os modelos contínuos tem para descrever o termo de cavitação. 


\section{Capítulo 5}

\section{Conclusão e perspectivas}

Neste trabalho, estudamos a solvatação dos carbonatos de etileno e de propileno. As moléculas foram estudadas em fase gasosa e em solução aquosa, onde foram usados métodos de solvatação implícita (PCM) e modelos de solvatação explícita (simulações com o método MC).

A principal conclusão deste trabalho é que a solvatação das moléculas de EC e PC são rigorosamente equivalentes, apesar do grupo metil do PC tornar esta molécula, em princípio, mais hidrofóbica que o EC. Isto fica evidenciado em todos os resultados apresentados. Desta forma, concluímos que o grupo metil têm pouca influência no processo de solvatação do PC. Nosso melhor resultado para a energia livre de solvatação das moléculas, usando simulações com o método Monte Carlo e a teoria de perturbação termodinâmica, foi de $-15,1 \pm 0,8 \mathrm{kcal} / \mathrm{mol}$ para o EC e de $-15,3 \pm 1,2 \mathrm{kcal} / \mathrm{mol}$ para o PC, sendo que a principal contribuição para este valor vem do termo eletrostático. Ambas as moléculas são, desta forma, bastante estáveis em solução aquosa.

A razão de tamanha estabilidade está relacionada a dois fatores. O primeiro é o momento de dipolo que, de acordo com os resultados obtidos com o PCM, aumenta em relação a fase gasosa, de 5,39 D (EC) e 5,61 D (PC) para 7,35 D (EC) e 7,61 D (PC) em solução. O segundo fator são as ligações de hidrogênio ao redor do oxigênio O1, que formam um aglomerado com dipolo ainda maior. 
De fato, nossos resultados mostram que são formadas em média, o mesmo número de 1,4 LH em ambos os carbonatos, com características muito próximas (mesma distância, orientação) e com uma energia de ligação de $-6,3 \pm 0,7 \mathrm{kcal} / \mathrm{mol}$. O dipolo médio dos aglomerados entre os carbonatos e suas ligações de hidrogênio foi de 9,9 $9 \pm 0,2 \mathrm{D}$ para o EC e de 10,6 \pm 0, $2 \mathrm{D}$ para o PC. A presença do grupo hidrofóbico nas moléculas parece inibir a formação de ligações de hidrogênio nos oxigênios O2 e O3, já que foram observadas ligações de hidrogênio apenas no oxigênio O1 dos carbonatos. Por essa razão este oxigênio é muito pouco afetado pela cadeia hidrofóbica e inferimos que mesmo se grupos maiores que o fossem agregados ao carbono $\mathrm{C} 2$, estes não afetariam significativamente as ligações de hidrogênio, que constituem a principal interação entre a parte hidrofílica da molécula e as águas.

Um fator limitante no estudo de sistemas maiores, evidentemente, é o custo computacional. No que se refere ao cálculo da energia livre de solvatação, vimos que os cálculos usando FEP requerem uma série de simulações computacionais. Existe na literatura uma técnica alternativa, conhecida como método de inserção de Widom [49], que permite obter $\Delta G_{\text {solv }}$ com apenas uma simulação. Na realidade, em geral o que se calcula é o potencial químico, mas este pode ser relacionado com a energia livre de solvatação. Este método tem sido usado na literatura no estudo da solubilidade de sistemas gasosos apolares em solução aquosa. Os estudos que aparecem se resumem a gases nobres e metano [85-88]. A dificuldade de extensão deste método para sistemas maiores está relacionada a problemas na convergência. Esta dificuldade está relacionada a forma como a amostragem é feita, e por esta razão, tipos especiais de amostragem tem de ser usadas. Por esta razão, a implementação não é trivial e não faz parte deste projeto. Mas, por ser um método conceitualmente simples e capaz de produzir bons resultados, trata-se de um método bastante promissor e é uma perspectiva interessante para o prosseguimento deste trabalho. 


\section{Referências Bibliográficas}

[1] JEFFSOL. Alkylene carbonates. Technical bulletin. Huntsman Corporation, Austin, TX, 2001.

[2] SHAIKH, A. A. G.; SIVARAM, S. Organic carbonates. Chemical Reviews, v. 96, n. 3, p. 951-976, 1996.

[3] SCHAFFNER, B.; SCHAFFNER, F.; VEREVKIN, S. P.; BORNER, A. Organic carbonates as solvents in synthesis and catalysis. Chemical Reviews, v. 110, n. 8, p. $4554-4581,2010$.

[4] VEREVKIn, S.; TOKTONOV, A.; CHERNYAK, Y.; SCHAFFNER, B.; BORNER, A. Vapour pressure and enthalpy of vaporization of cyclic alkylene carbonates. Fluid Phase Equilibria, Amsterdam, v. 268, n. 1-2, p. 1-6, 2008.

[5] CHERNYAK, Y. Dielectric constant, dipole moment, and solubility parameters of some cyclic acid esters. Journal of Chemical \& Engineering Data, v. 51, n. 2, p. 416-418, 2006.

[6] VEREVKIN, S.; EMEL'YANENKO, V.; TOKTONOV, A.; CHERNYAK, Y.; SCHAFFNER, B.; BORNER, A. Cyclic alkylene carbonates. Experiment and first principle calculations for prediction of thermochemical properties. The Journal of Chemical Thermodynamics, v. 40, n. 9, p. 1428-1432, 2008. 
[7] WANG, Y.; BALBUENA, P. Associations of alkyl carbonates: Intermolecular CH... O interactions. The Journal of Physical Chemistry A, v. 105, n. 43, p. 9972-9982, 2001.

[8] SOEtens, J.; Millot, C.; MAIGRET, B.; BAKO, I. Molecular Dynamics simulation and X-ray diffraction studies of ethylene carbonate, propylene carbonate and dimethyl carbonate in liquid phase. Journal of Molecular Liquids, v. 92, n. 3, p. 201-216, 2001.

[9] SILVA, L. B.; FREITAS, L. C. G. Structural and thermodynamic properties of liquid ethylene carbonate and propylene carbonate by Monte Carlo simulations. Journal of Molecular Structure-Theochem, v. 806, n. 1-3, p. 23-34, 2007.

[10] SOETEnS, J.; MILlOT, C.; MAIGRET, B. Molecular dynamics simulation of $\mathrm{Li}^{+} \mathrm{BF}_{4}^{-}$in ethylene carbonate, propylene carbonate, and dimethyl carbonate solvents. The Journal of Physical Chemistry A, v. 102, n. 7, p. 1055-1061, 1998.

[11] BORODIN, O.; SMITH, G. LiTFSi structure and transport in ethylene carbonate from molecular dynamics simulations. The Journal of Physical Chemistry $B$, v. 110, n. 10, p. 4971-4977, 2006.

[12] BORODIN, O.; SMITH, G. Quantum chemistry and molecular dynamics simulation study of dimethyl carbonate: Ethylene carbonate electrolytes doped with LiPF. The Journal of Physical Chemistry B, v. 113, n. 6, p. 1763-1776, 2009.

[13] WANG, Y.; NAKAMURA, S.; UE, M.; BALBUEnA, P. Theoretical studies to understand surface chemistry on carbon anodes for lithium-ion batteries: Reduction mechanisms of ethylene carbonate. Journal of the American Chemical Society, Washington, v. 123, n. 47, p. 11708-11718, 2001. 
[14] LI, T.; BALBUENA, P. Theoretical studies of lithium perchlorate in ethylene carbonate, propylene carbonate, and their mixtures. Journal of the Electrochemical Society, v. 146, p. 3613, 1999.

[15] VAN GUNSTEREN, W.; BERENDSEN, H. Thermodynamic cycle integration by computer simulation as a tool for obtaining free energy differences in molecular chemistry. Journal of Computer-Aided Molecular Design, v. 1, n. 2, p. 171-176, 1987.

[16] COUtinho, K.; CABral, B. J. C.; CANUTO, S. Can larger dipoles solvate less? Solute-solvent hydrogen bond and the differential solvation of phenol and phenoxy. Chemical Physics Letters, Amsterdam, v. 399, n. 4-6, p. 534-538, 2004.

[17] VIANNA, J. D. M.; FAZZIO, A.; CANUTO, S. Teoria Quântica de Moléculas e Sólidos. Editora Livraria da Física, 2004.

[18] SZABO, A.; OSTLUND, N. S. Modern Quantum Chemistry: Introduction to Advanced Electronic Structure Theory. Dover Publications, 1996.

[19] JENSEN, F. Introduction to computational chemistry. Wiley, 2007.

[20] SLATER, J. C. Atomic shielding constants. Phys. Rev., v. 36, n. 1, p. 57-64, Jul 1930 .

[21] BOYS, S. F. Electronic wave functions. I. A general method of calculation for the stationary states of any molecular system. Proceedings of the Royal Society of London. Series A. Mathematical and Physical Sciences, v. 200, n. 1063, p. $542-554,1950$.

[22] JALBOUT, A.; NAZARI, F.; TURKER, L. Gaussian-based computations in molecular science. Journal of Molecular Structure: THEOCHEM, v. 671, n. 1-3, p. 1-21, 2004. 
[23] GOLDSTONE, J. Derivation of the Brueckner many-body theory. Proceedings of The Royal Society A: Mathematical, Physical and Engineering Sciences, v. 239, p. 267-279, 1957.

[24] BARTlETT, R.; MUSIAE, M. Coupled-cluster theory in quantum chemistry. Reviews of modern physics, v. 79, n. 1, p. 291, 2007.

[25] HelGakeR, T.; GAUSS, J.; JØRGENSEN, P.; OLSEN, J. The prediction of molecular equilibrium structures by the standard electronic wave functions. The Journal of chemical physics, v. 106, n. 15, p. 6430, 1997.

[26] COUTINHO, K.; GUEDES, R.; COSTA CABRAL, B.; CANUTO, S. Electronic polarization of liquid water: converged Monte Carlo/Quantum Mechanics results for the multipole moments. Chemical physics letters, v. 369, n. 3-4, p. 345-353, 2003.

[27] MORGOn, N.; COUTINHO, K.(Ed.) Métodos de química teórica e modelagem molecular. Editora Livraria da Física, 2007.

[28] ATKINS, P.; FRIEDMAN, R. Molecular quantum mechanics. Oxford university press Oxford, 1997. v. 3.

[29] MCWEENY, R. Methods of molecular quantum mechanics. London, New York, Academic Press, 1989.

[30] BRENEMAN, C.; WIBERG, K. Determining atom-centered monopoles from molecular electrostatic potentials. The need for high sampling density in formamide conformational analysis. Journal of Computational Chemistry, v. 11, n. 3, p. 361-373, 1990. 
[31] OROZCO, M.; LUQUE, F. Theoretical methods for the description of the solvent effect in biomolecular systems. Chemical Reviews, v. 100, n. 11, p. 4187-4226, 2000.

[32] BEN-NAIM, A. A simple model for demonstrating the relation between solubility, hydrophobic interaction, and structural changes in the solvent. The Journal of Physical Chemistry, v. 82, n. 8, p. 874-885, 1978.

[33] BEN-NAIM, A.; MARCUS, Y. Solvation thermodynamics of nonionic solutes. The Journal of chemical physics, v. 81, p. 2016, 1984.

[34] CHIPOT, C.; POHORILLE, A. Free energy calculations: theory and applications in Chemistry and Biology. Springer Verlag, 2007. v. 86.

[35] COSSI, M.; BARONE, V.; CAMMI, R.; TOMASI, J. Ab initio study of solvated molecules: a new implementation of the polarizable continuum model. Chemical physics letters, v. 255, n. 4-6, p. 327-335, 1996.

[36] BORN, M. Volumes and hydration warmth of ions. Zeitschrift Fur Physik, v. 1, p. $45-48,1920$.

[37] ONSAGER, L. Electric moments of molecules in liquids. Journal of the American Chemical Society, Washington, v. 58, p. 1486-1493, 1936.

[38] KIRKWOOD, J. G. On the theory of dielectric polarization. Journal of Chemical Physics, New York, v. 4, n. 9, p. 592-601, 1936.

[39] TAPIA, O.; GOSCINSKI, O. Self-consistent reaction field theory of solvent effects. Molecular Physics, v. 29, n. 6, p. 1653-1661, 1975.

[40] RIVAIL, J.; RINALDI, D. A quantum chemical approach to dielectric solvent effects in molecular liquids. Chemical Physics, v. 18, n. 1-2, p. 233-242, 1976. 
[41] MIERTUS, S.; SCROCCO, E.; TOMASI, J. Eletrostatic interaction of a solute with a continuum - a direct utilization of $a b$ initio molecular potentials for the prevision of solvent effects. Journal of Chemical Physics, New York, v. 55, n. 1, p. $117-129,1981$.

[42] TOMASI, J.; PERSICO, M. Molecular-interactions in solution - an overview of methods based on continuous distributions of the solvent. Chemical Reviews, v. 94, n. 7, p. 2027-2094, 1994.

[43] TOMASI, J.; MENNUCCI, B.; CAMMI, R. Quantum mechanical continuum solvation models. Chemical reviews, v. 105, n. 8, p. 2999-3094, 2005.

[44] MENNUCCI, B.; CAMMI, R. Continuum solvation models in chemical physics: from theory to applications. John Wiley \& Sons, Ltd, 2007.

[45] CANCES, E.; MENNUCCI, B.; TOMASI, J. A new integral equation formalism for the polarizable continuum model: Theoretical background and applications to isotropic and anisotropic dielectrics. Journal of Chemical Physics, Woodbury, v. 107, n. 8, p. 3032-3041, 1997.

[46] JORGENSEN, W.; MAXWELL, D.; TIRADO-RIVES, J. Development and testing of the OPLS all-atom force field on conformational energetics and properties of organic liquids. Journal of the American Chemical Society, Washington, v. 118, n. 45, p. 11225-11236, 1996.

[47] CORNELL, W.; CIEPLAK, P.; BAYLY, C.; GOULD, I.; MERZ, K.; FERGUSON, D.; SPEllmeYeR, D.; FOX, T.; CAlDWEll, J.; KOllman, P. A second generation force field for the simulation of proteins, nucleic acids, and organic molecules. Journal of the American Chemical Society, Washington, v. 117, n. 19, p. 5179-5197, 1995. 
[48] Allen, M. P.; TILDESLEY, D. J. Computer simulation of liquids. New York, NY, USA: Clarendon Press, 1987.

[49] FRENKEL, D.; SMIT, B. Understanding molecular simulation: from algorithms to applications. Academic Press, Inc. Orlando, FL, USA, 2002.

[50] COUTINHO, K.; CANUTO, S. DICE: A Monte Carlo program for molecular liquid simulation, v. 2.9. University of São Paulo, São Paulo, 2003.

[51] COUTINHO, K. Modelo discreto de solvente. Solvatocromismo no espectro de absorção molecular. 1997. Tese (Doutorado em Física) - Instituto de Física, Universidade de São Paulo, São Paulo, 1997.

[52] GEORG, H. Efeitos do meio em propriedades conformacionais e eletrônicas de moléculas. 2006. Tese (Doutorado em Física) - Instituto de Física, Universidade de São Paulo, São Paulo, 2006.

[53] BARLETTE, V.; FREITAS, L. Termodinâmica estatística de líquidos com o método de Monte Carlo I. Metodologia. Química Nova, v. 22, n. 2, p. 254, 1999.

[54] GEORG, H.; COUTINHO, K.; CANUTO, S. Solvent effects on the UV-visible absorption spectrum of benzophenone in water: A combined Monte Carlo/quantum mechanics study including solute polarization. The Journal of chemical physics, v. 126, p. $034507,2007$.

[55] CAnuto, S.; COUTinho, K.; TRZESniAK, D. New developments in Monte Carlo/quantum mechanics methodology. the solvatochromism of $\beta$-carotene in different solvents. Advances in Quantum Chemistry, v. 41, p. 161-183, 2002.

[56] ZWANZIG, R. High-temperature equation of state by a perturbation method. I. Nonpolar gases. The Journal of Chemical Physics, v. 22, p. 1420, 1954. 
[57] LEVESQUE, D.; VERLET, L. Perturbation theory and equation of state for fluids. Phys. Rev., v. 182, n. 1, p. 307-316, 1969.

[58] BEVERIDGE, D.; DICAPUA, F. Free energy via molecular simulation: applications to chemical and biomolecular systems. Annual review of biophysics and biophysical chemistry, v. 18, n. 1, p. 431-492, 1989.

[59] KOLLMAN, P. Free energy calculations: Applications to chemical and biochemical phenomena. Chemical Reviews, v. 93, n. 7, p. 2395-2417, 1993.

[60] BENNETT, C. Efficient estimation of free energy differences from Monte Carlo data. Journal of Computational Physics, v. 22, n. 2, p. 245-268, 1976.

[61] BASH, P.; SINGH, U.; LANGRIDGE, R.; KOLLMAN, P. Free energy calculations by computer simulation. Science, Washington, v. 236, n. 4801, p. 564, 1987.

[62] JORGENSEN, W.; BUCKNER, J.; BOUDON, S.; TIRADO-RIVES, J. Efficient computation of absolute free energies of binding by computer simulations. Application to the methane dimer in water. The Journal of chemical physics, v. 89, p. $3742,1988$.

[63] GEORG, H.; COUTINHO, K.; CANUTO, S. A look inside the cavity of hydrated $\alpha$-cyclodextrin: A computer simulation study. Chemical physics letters, v. 413, n. 1-3, p. 16-21, 2005.

[64] CANUTO, S.(Ed.) Solvation effects on molecules and biomolecules: Computational methods and applications. Springer Verlag, 2008. v. 6.

[65] CHATFIELD, C. The Analysis of Time Series: An Introduction. London: Chapman \& Hall/CRC, 2003. 
[66] FRISCH, M. J.; TRUCKS, G. W.; SCHLEGEL, H. B.; SCUSERIA, G. E.; ROBB, M. A.; CHEESEMAN, J. R.; MONTGOMERY, JR., J. A.; VREVEN, T.; KUDIN, K. N.; BURANT, J. C.; MILLAM, J. M.; IYENGAR, S. S.; TOMASI, J.; BARONE, V.; MENNUCCI, B.; COSSI, M.; SCALMANI, G.; REGA, N.; PETERSSON, G. A.; NAKATSUJI, H.; HADA, M.; EHARA, M.; TOYOTA, K.; FUKUDA, R.; HASEGAWA, J.; ISHIDA, M.; NAKAJIMA, T.; HONDA, Y.; KITAO, O.; NAKAI, H.; KLENE, M.; LI, X.; KNOX, J. E.; HRATCHIAN, H. P.; CROSS, J. B.; BAKKEN, V.; ADAMO, C.; JARAMILlO, J.; GOMPERTS, R.; STRATMANN, R. E.; YAZYEV, O.; AUSTIN, A. J.; CAMMI, R.; POMELLI, C.; OCHTERSKI, J. W.; AYALA, P. Y.; MOROKUMA, K.; VOTH, G. A.; SALVADOR, P.; DANNENBERG, J. J.; ZAKRZEWSKI, V. G.; DAPPRICH, S.; DANIELS, A. D.; STRAIN, M. C.; FARKAS, O.; MALICK, D. K.; RABUCK, A. D.; RAGHAVACHARI, K.; FORESMAN, J. B.; ORTIZ, J. V.; CUI, Q.; BABOUL, A. G.; ClifFORD, S.; CIOSLOWSKI, J.; STEFANOV, B. B.; LIU, G.; LIASHENKO, A.; PISKORZ, P.; KOMAROMI, I.; MARTIN, R. L.; FOX, D. J.; KEITH, T.; AL-LAHAM, M. A.; PENG, C. Y.; NANAYAKKARA, A.; CHALLACOMBE, M.; GILL, P. M. W.; JOHNSON, B.; CHEN, W.; WONG, M. W.; GOnZAleZ, C.; POPlE, J. A. Gaussian 03, Revision D.01. Gaussian, Inc., Wallingford, CT, 2004.

[67] BROWN, C. The crystal structure of ethylene carbonate. Acta Crystallographica, v. 7, n. 1, p. 92-96, 1954.

[68] ANGELL, C. L. The Infra-Red spectra and structure of ethylene carbonate. Trans. Faraday Soc., v. 52, p. 1178-1183, 1956.

[69] DURIG, J.; COULTER, G.; WERTZ, D. Far-Infrared spectra and structure of small ring compounds. Ethylene carbonate, $\gamma$-butyrolactone, and cyclopentanone. Journal of Molecular Spectroscopy, v. 27, n. 1-4, p. 285-295, 1968. 
[70] LEGON, A. Equilibrium conformations of four-and five-membered cyclic molecules in the gas phase: determination and classification. Chemical Reviews, v. 80, n. 3, p. 231-262, 1980.

[71] FORTUNATO, B.; MIRONE, P.; FINI, G. Infrared and Raman spectra and vibrational assignment of ethylene carbonate. Spectrochimica Acta Part A: Molecular Spectroscopy, v. 27, n. 9, p. 1917 - 1927, 1971.

[72] ALOnSO, J.; CERVELlati, R.; DEGli ESPOSTI, A.; LISTER, D.; PALMIERI, P. Microwave spectrum and ab initio computations for ethylene carbonate. Part 1. Conformation and ring inversion. Journal of the Chemical Society, Faraday Transactions 2: Molecular and Chemical Physics, v. 82, n. 3, p. 337-356, 1986.

[73] MATIAS, P.; JEFFREY, G.; WINGERT, L.; RUBLE, J. Single crystal neutron diffraction analysis $(15 \mathrm{~K})$ and ab initio molecular orbital calculations for ethylene carbonate. Journal of Molecular Structure: THEOCHEM, v. 184, n. 3-4, p. 247$260,1989$.

[74] ARJUNAN, V.; SARAVANAN, I.; RAVINDRAN, P.; MOHAN, S. FTIR, FTRaman, ab initio and density functional studies on 4-methyl-1, 3-dioxolan-2-one and 4, 5-dichloro-1, 3-dioxolan-2-one. Spectrochimica Acta Part A: Molecular and Biomolecular Spectroscopy, v. 77, n. 1, p. 28-35, 2010.

[75] KEMPA, R.; LEE, W. H. The dipole moments of some cyclic carbonates. $J$. Chem. Soc., v. 1958, p. 1936-1938, 1958.

[76] BARONE, V.; COSSI, M.; TOMASI, J. A new definition of cavities for the computation of solvation free energies by the polarizable continuum model. Journal of Chemical Physics, Woodbury, v. 107, n. 8, p. 3210-3221, 1997. 
[77] KLAMT, A.; MENNUCCI, B.; TOMASI, J.; BARONE, V.; CURUTCHET, C.; OROZCO, M.; LUQUE, F. On the performance of continuum solvation methods. a comment "On universal approaches to solvation modeling". Accounts of chemical research, v. 42, n. 4, p. 489-492, 2009.

[78] HO, J.; KLAMT, A.; COOTE, M. L. Comment on the Correct Use of Continuum Solvent Models. The Journal of Physical Chemistry A, v. 114, n. 51, p. 13442$13444,2010$.

[79] GUILLOT, B. A reappraisal of what we have learnt during three decades of computer simulations on water. Journal of Molecular Liquids, v. 101, p. 219, 2002.

[80] Berendsen, H.; POStMA, J.; GUnSteren, W. V.; Hermans, J. Interaction models for water in relation to protein hydration. Dordrecht: Reidel, 1981.

[81] MEZEI, M.; BEVERIDGE, D. L. Theoretical studies of hydrogen bonding in liquid water and dilute aqueous solutions. Journal of Chemical Physics, New York, v. 74, n. 1, p. 622-632, 1981.

[82] SCEATS, M. G.; RICE, S. A. The water-water pair potencial near the hydrogenbonded equilibrium configuration. Journal of Chemical Physics, New York, v. 72, n. 5 , p. 3236-3247, 1980.

[83] COUTinho, K.; CANUTO, S. The sequential Monte Carlo/Quantum Mechanics methodology. Application to the solvent effects in the stokes shift of acetone in water. Journal of Molecular Structure-Theochem, v. 632, p. 235, 2003.

[84] GEORG, H. C.; COUTINHO, K.; CANUTO, S. A sequential Monte Carlo/Quantum Mechanics study of the hydrogen-bond interaction and the solvatochromic 
shift of the $\left.\mathrm{n}-\pi^{*}\right)$ transition of acrolein in water. Journal of Chemical Physics, Woodbury, v. 123, p. 124307, 2005.

[85] DYER, P.; DOCHERTY, H.; CUMMINGS, P. The importance of polarizability in the modeling of solubility: Quantifying the effect of solute polarizability on the solubility of small nonpolar solutes in popular models of water. The Journal of chemical physics, v. 129, p. 024508, 2008.

[86] DOCHERTY, H.; GALINDO, A.; VEGA, C.; SANZ, E. A potential model for methane in water describing correctly the solubility of the gas and the properties of the methane hydrate. The Journal of chemical physics, v. 125, p. 074510, 2006.

[87] PASCHEK, D. How does solute-polarization affect the hydrophobic hydration of methane? Zeitschrift für Physikalische Chemie, v. 223, p. 1091-1104, 2009.

[88] PASCHEK, D. Temperature dependence of the hydrophobic hydration and interaction of simple solutes: An examination of five popular water models. The Journal of chemical physics, v. 120, p. 6674, 2004. 